\title{
MIXING IN NUMERICAL MODELS OF MANTLE CONVECTION INCORPORATING PLATE KINEMATICS
}

Michael Gurnis and Geoffrey F. Davies

Research School of Earth Sciences, Australian National University, Canberra

\begin{abstract}
The process by which subducted lithosphere is mixed by mantle convection is investigated in numerical calculations. The resul ts show that the observed isotopic heterogeneity of mantle sources and their ancient (1-2 b.y.) apparent ages are consistent with convective mixing. Passive tracers, which are introduced below "trenches," are efficiently dispersed, but nonetheless, heterogeneities in tracer density with a large range of length scales are observed to persist for 40 or more transit times (one transit time is the time to travel the fluid depth with the boundary velocity). In particular, there is a strong tendency to form high-density folds of the tracer strings, which persist much longer than simple shearing indicates. The folds persist because there is a strong tendency for material that enters the flow at the margins of cells to be transferred to adjacent cells, where it is "unmixed." When the simulations are scaled to the whole mantle, the tight clumps (folds) of tracers are shown to persist for up to 1-2 b.y. There is also a tendency for large-scale convection cells to remain isolated from recycled material for 1-2 b.y. These results are consistent with the significant chemical heterogeneity of the mantle as revealed by isotopic studies of oceanic basalts. Despite the spatial heterogeneity in tracer density, the average time tracers remain in the box from subduction at trenches to sampling at ridges (i.e., the residence time) is well constrained and within $20 \%$ of the mean residence time expected from an analytic model in which tracers are assumed to be sampled randomly. Model ages of the mantle that explicitly incorporate increased convection rates in the past and assume random sampling of heterogeneities bracket the -2 b.y. apparent $\mathrm{Pb}-\mathrm{Pb}$ and $\mathrm{Rb}-\mathrm{Sr}$ isochrons of midocean ridge basalts and oceanic island basalts. The conclusion of persistent spatial heterogeneity is different from the conclusions drawn from other studies. The different conclusions result, primarily, from our emphasis on the details of spatial variations as opposed to some average of the mixing, from a difference in flow unsteadiness, and from the different ways tracers have been introduced into the flow.
\end{abstract}

\section{Introduction}

The purpose of this paper is to start constructing models of mantle mixing and crust-mantle recycling that are constrained by processes that are known to doninate the recent geological record: the kinematics of lithospheric plates, the fractionation beneath ridges, and the subduction

Copyright 1986 by the American Geophysical Union.

Paper number $4 \mathrm{~B} 5234$.

$0148-0227 / 86 / 004 \mathrm{~B}-5234 \$ 05.00$ of chemically anomalous material at oceanic trenches. Only simplified calculations are presented here, but it is hoped they will pave the way to better thermochemical simulations of the mantle.

These mixing calculations, are motivated by a large body of chemical and geological data, some of which has demonstrated that recycling of crustal material into the deep mantle is a fundamental process. Some of these observations, whlch are brlefly reviewed in the next section, include the 1sotopic heterogeneity of the mantle, the persistence of these isotoplc heterogeneities for billions of years, and other isotople slgnatures that imply extensive anclent recycling of cristal material.

Conservation of mas's dictates that there must be large scale flow associated with plate motion. Because the motion of the lithosphere is the surface of the convecting mantle, any model of larige scale mantle flow must be constrained by plate motion; .. In other words the kinematics of the lithosphere can be used as a boundary condition on deep mantle flow [Hager and $0^{\prime}$ Connell, 1979]. Furthermore, chenical anomalies are injected into the mantle below oceanic trenches where the large scale flow is descending.

Plate kinematics is characterized by the uniform velocity across plates, the symmetrical spreading at ridges, and the asymmetrical convergence at trenches. Furthermore, a fundamental feature, perhaps not well appreciated, is that plate kinematics is unsteady: plates grow and shrink, plates are consumed, and plates rearrange on time scales comparable to convective overturn times. This unsteadiness is manifest by the relative migration of ridges and trenches. Because we now understand plate kinematics in broad outline, we can constrain this large scale mode of mantle convection, including its intrinsic unsteadiness. In this paper, convective mixing calculations are presented that are constrained by these features of plate motion.

To explore the consequences of mixing in flows constrained by plate kinematics and the geochemical observations that suggest recycling, we set up a two-dimensional numerical model of thermal convection in $a$ box and introduced passive tracers into the flow. With this model, residence times are calculated, and simple observations of mixing are made. Two fundamental features of the calculations are that unsteadiness of the flow is driven by the migration of ridges and trenches and that passive tracers simulating chemical tracers are introduced at trenches. The basic features of the convection and tracer calculations are outlined in the next section. Then, a detailed account of one case is given, including qualitative features of mixing, the strain experienced by the subducted material, and the residence times of the tracers. The features found in this model are shown to be 
general phenomena occurring in a variety of convection models through a large parameter range. The basic fluid dynamics of this mixing are also studied in flows specified by simple analytic stream functions. A simple analytic model of recycling that assumes that tracer sampling is random is then developed; the model enables the behavior of the numerical mixing models to be simply characterized and scaled to the mantle. Finally, the effect of increased convection rates in the past on the time scalings is explored, and the mixing calculations presented here are compared with other calculations.

\section{Large-Scale Recycling}

The observations that have motivated the calculations to follow are first briefly reviewed. There is a diversity in the $\mathrm{Sr}, \mathrm{Nd}, \mathrm{Pb}$, and He isotopic ratios of midocean ridge basalts (MORB'S) and oceanic island basalts (OIB's) and this indicates that the mantle is isotopically heterogeneous. Simple correlations are not found between the different isotope systems. For example, oceanic basalts do not have a simple linear correlation between the $87 \mathrm{Sr} / 86 \mathrm{Sr}$ versus $143 \mathrm{Nd} / 144 \mathrm{Nd}$ ratios, as was originally thought [Wasserburg and DePaolo, 1979]. Some island $f i e l d s$ (such as Samoa and st. Helena) fall of $f$ the mantle array, and some islands have $143 \mathrm{Nd} / 144 \mathrm{Nd}$ ratios less than "primitive," for example, Kerguelen [White and Hofmann, 1982]. This means that the mantle is more heterogeneous than accounted for by two reservolrs and that at least one reservoir must be more enriched than primitive [White and Hofmann, 1982]. A much more extreme case is found for the $87 \mathrm{sr} / 86 \mathrm{Sr}$ versus $206 \mathrm{~Pb} / 204 \mathrm{~Pb}$ ratios, which show extreme scatter [Sun and Hanson, 1975], and this indlcates that the observed isotope ratios cannot be explained by simple mixing of two components. Although this only demonstrates the mantle has at least three isotopically distinct reservoirs, an equally plausible explanation, and perhaps one that is geologically more reasonable, is the existence of many diverse reservoirs entralned throughout the mantle [Davies, 1984a; Zindler et al., 1984].

A time scale is also indicated by the spread in isotope ratios. The linear correlations of the $\mathrm{Pb}$ ratios for oceanic island basalts on the $207 \mathrm{~Pb} / 204 \mathrm{~Pb}$ versus $206 \mathrm{~Pb} / 204 \mathrm{~Pb}$ diagram and on the $208 \mathrm{~Pb} / 204 \mathrm{~Pb}$ versus $206 \mathrm{~Pb} / 204 \mathrm{~Pb}$ diagram can be interpreted as if they were isochrons with an age of about $1.8 \mathrm{~b} . \mathrm{y}$. [Church and Tatsumoto, 1975; Tatsumoto, 1978; Chase, 1981]. This apparent age is corroborated by $\mathrm{Rb}-\mathrm{Sr}$ isotope systematics which implies an age of $1.6 \mathrm{~b} . \mathrm{y}$. [Brooks et al., 1976]. The correspondence between the two apparent ages suggests that isotopic reservoirs (however many there are) may have persisted, on average, for 1 to $2 \mathrm{b.y}$.

Chase [1981] has presented a self-consistent model of oceanic island lead that gives further insight into the possible cause of mantle heterogeneity. When two-stage models are calculated for oceanic islands individually, the same primary parent to daughter ratio results, and this implies that the source region for all the islands may have been the same. Because the island arrays intersect tightly in the MORB field [cf. Davies, 1984a], Chase [1981] proposed that ancient subducted MORB was the primary OIB source. Chase's interpretation explicitly involves more than three ancient mantle source types. This involvement of ancient MORB as the source for present-day OIB is consistent with crustal recycling.

Many of the isotopic signatures of oceanic basalts can be explained by crustal material that has been recycled into the mantle. Hofmann and White [1982] argued that the chemical characteristics of many OIB's could best be satisfied by a source composed of recycled oceanic crust and sediments that would have high incompatible element concentrations, allowing basalts to be produced with reasonable degrees of partial melt (i.e., 10 - 20\%). In addition, the high concentrations of the incompatible elements help satisfy, for example, the $\mathrm{Sr}$ and $\mathrm{Pb}$ 1sotopes, which indlcate time-integrated enrichment of $\mathrm{Rb}$ and $U$, respectively. Hofmann and White argue that the high $K, U$, and $T h$ concentrations could give the necessary heat production allowing the recycled material to become diapirically unstable; this would give the OIB's their "hot spot" characteristics.

Important corroborating evidence for recycling has come from helium. Mantle rocks cycled through the oceanic crust (subjected to magmatic fractionation at ridges) lose helium by degassing. Segments of the mantle previously recycled should be strongly depleted in $\mathrm{He}$, and hence have low $3 \mathrm{He} / 4 \mathrm{He}$ ratios. The islands of Tahiti, Tristan da Cunha, and Gough have as high or higher $87 \mathrm{sr} / 86 \mathrm{Sr}$ ratios compared with Hawail, but significantly smaller $3 \mathrm{He} / 4 \mathrm{He}$ ratios than MORB. An interpretation of these isotope systematics is that not only has there been preferential degassing but there has also been time integrated enrichment of $\mathrm{Rb}$ compared with $\mathrm{Sr}$ in the sources of some islands (like Tahiti, Tristan da Cunha, and Gough). A simple and a plausible actualistic hypothesis is that the sources for some oceanic islands have been cycled through the oceanic crust [Kurz et al., 1982]. The rare gases also show that some islands may be more primitive [Kurz et al., 1983; Allègre et al., 1983], but this interpretation has been claimed to be model dependent [Fisher, 1985].

There is also a large base of data that demonstrates that sediments subduct in significant quantities. Sediments have been recognized in the tensional grabens in 1 ithosphere about to subduct [cf. Isacks et al., 1968], and sediment-filled grabens have been detected by seismic reflection under overriding plates [see Hilde, 1983]. Geologic and mass balances deduced from recent Deep Sea Drilling Project/International Program of Ocean Drilling drilling in trenches requires that at least $50 \%$ of sediments reaching trenches subduct [Von Huene et al., 1982; Hussong and Uyeda, 1982]. The detection of $10_{\mathrm{Be}}$ anomalies in island are volcanics (IAV's), but not in other volcanics, demonstrates the subduction of sediments [Brown et al., 1982].

The geological data do not prove sediments and oceanic crust subduct into the deep mantle because it is possible they are largely tapped off by IAV's. Sediment of $f$-tapping has to exist, at least to a small extent, to explain the $10_{\mathrm{Be}}$ anomalies. The sources of IAV can be constrained by using $\mathrm{Sr}, \mathrm{Nd}$, and $\mathrm{Pb}$ isotopes as tracers. 
Unfortunately, IAV's show increased amounts of contamination in more continental settings [White and Patchett, 1984]; therefore only those settings entirely oceanic can be used to test the incorporation of crust and sediments into IAV's by using isotopes as tracers.

A detailed study of the $\mathrm{Pb}$ isotope variations in Mariana arc andesites and oceanic sediments converging toward the trench is presented by Meijer [1976]. The data clearly demonstrate that the Mariana Frontal Arc and active arc lavas are isotopically indistinguishable from MORB. Because the sediments converging toward the Mariana trench have such high $207 \mathrm{pb} / 204 \mathrm{pb}$ (and $208 \mathrm{~Pb} / 204 \mathrm{~Pb}$ ) ratios compared with $206 \mathrm{~Pb} / 204 \mathrm{~Pb}$ and because the concentration of $\mathrm{Pb}$ in the sediment is approximately 25 times the concentration in Mariana arc volcanics and oceanic basalts, even a small amount of sediment contaminating the IAV source would give $\mathrm{Pb}$ isotopic ratios significantly different from those observed. Meijer [1976] calculates that the sediment contribution to IAV cannot be greater than $1 \%$. It follows, at least in the Marianas, that most sediment and crust is recycled into the deep mantle.

The data reviewed here indicate the existence of mantle heterogeneities that have persisted for billions of years. At least some of the isotopic variation does not seem to be explicable in terms of uniform mantle layers [see also Davies, 1984a]. This poses the question of how heterogeneities can persist for so long in the presence of convection that must exist in each layer, whether there is one mantle layer or several. This is the question addressed in this paper.

\section{Convection Model and outline of Tracer Calculations}

In this section we outline a procedure to study mixing in unsteady mantle convection by calculating the advection of passive tracers through a two-dimensional box convecting with constant Newtonian viscosity. By passive tracer we mean that the tracer generates no buoyancy of its own, that the tracer does not modify the flow in any way, and that the tracer is simply advected by the background flow. The aspect ratio of the box (width/depth) is 4 . The top boundary velocity is imposed on the convecting fluid in piecewise constant segments, and each segment implicitly represents a lithospheric plate; a thorough description of this type of convection model is found in Davies [1986]. Because the boundary between two segments can also move, two important features of plate tectonics are simulated: the constant velocity across a plate and the tendency of trenches and $r i d g e s$ to migrate.

In these calculations, lengths are scaled by the box depth, $D$, the temperatures by $\Delta T$, defined below, and the velocities by

$$
v_{0}=\frac{g \alpha \rho \Delta T D^{2}}{n}
$$

where $g$ is the acceleration due to gravity, $\alpha$ the volumetric coefficient of thermal expansion, $\rho$ the density, and $n$ the dynamic viscosity.

An important aspect of the models presented here is the presence of both boundary and thermal buoyancy forces. These forces are controlled by the Rayleigh number, Ra, and the Peclet number, $\mathrm{Pe}$

$$
\begin{gathered}
\mathrm{Ra}=\frac{\mathrm{g} \alpha \rho \Delta \mathrm{T} \mathrm{D}^{3}}{\mathrm{k} \pi} \\
\mathrm{Pe}=\frac{\mathrm{DU}_{\mathrm{b}}}{\mathrm{k}}
\end{gathered}
$$

where $k$ is the thermal diffusivity and $U_{b}$ the top boundary velocity. When the fluid is heated from within, $\Delta \mathrm{T}$ can be defined as

$$
\Delta \mathrm{T}=\frac{\mathrm{H} \mathrm{D} \mathrm{D}^{2}}{\mathrm{~K}}
$$

where $H$ is the rate of internal heat generation per unit volume and $K$ is the thermal conductivity. If we assume all the heat emerging from the earth's interior, $Q$, is generated within the mantle, then we can obtain an upper limit to $\mathrm{H}$

$$
H<\frac{Q}{V_{m}}
$$

where $V_{m}$ is again the volume of the mantle. When $\mathrm{Ra}$ is defined in terms of a temperature difference, the heating mode appropriate for upper mantle convection, then we will denote it as $\mathrm{Ra}_{\mathrm{T}}$; in (2). $\Delta T$ is then the temperature difference between the top of the mantle and the base of the upper mantle. For an internally heated fluid, the approximate heating mode for whole-mantle convection, the Rayleigh number will be denoted as $\mathrm{Ra}_{\mathrm{q}}$.

The time variable used in the convection model is normalized to the transit time, the time needed to travel the fluid depth with a characteristic velocity:

$$
\begin{gathered}
t_{t}^{\prime}=\frac{D}{U_{b}} \\
t_{t}=\frac{t^{\prime} v_{0}}{D}=\frac{R a}{P e}=\frac{1}{u_{b}}
\end{gathered}
$$

where $u_{b}$ is the dimensionless boundary velocity of the fluid: $u_{b}=U_{b} / v_{o}$. The $t$ ' $t$ is dimensional, while $t_{t}$ is not.

The boundary conditions of the model are

$$
\begin{array}{ll}
\text { All boundaries: } \Psi=0 \\
\text { Sides: } & \omega=0 \\
& \partial \mathrm{T} / \partial \mathrm{x}=0 \\
\text { Top: } & \partial \Psi / \partial \mathrm{y}=\mathrm{u}_{\mathrm{b}} \mathrm{U} u(\mathrm{x}, \mathrm{t}) \\
& \mathrm{T}=0 \\
\text { Bottom: } & \begin{array}{l}
\omega=0 \\
\end{array} \\
& \mathrm{~T}=1, \mathrm{~T} / \partial \mathrm{y}=0
\end{array}
$$

where $\omega$ is the vorticity and the stream function, $\Psi$, is defined as

$$
u_{x}=\frac{\partial \Psi}{\partial y} \quad u_{y}=-\frac{\partial \Psi}{\partial x}
$$


TABLE 1. Values of Numerical Parameters: Primary Quantities

\begin{tabular}{|c|c|c|}
\hline Par ameter & Description & Value \\
\hline $\bar{\alpha}$ & $\begin{array}{l}\text { Coefficient of } \\
\text { thermal expansion }\end{array}$ & $3 \times 10^{-5} \mathrm{~K}^{-1}$ \\
\hline$\rho$ & Density & $4 \times 10^{3} \mathrm{~kg} \mathrm{~m}^{-3}$ \\
\hline 8 & $\begin{array}{l}\text { Gravitational } \\
\text { acceleration }\end{array}$ & $10 \mathrm{~m} \mathrm{~s}^{-2}$ \\
\hline D & $\begin{array}{c}\text { Depth of convection } \\
\text { Whole mantle } \\
\text { Upper mantle }\end{array}$ & $\begin{array}{lll}3 & \times 10^{6} \mathrm{~m} \\
7 & \times 10^{5} \mathrm{~m}\end{array}$ \\
\hline $\mathbf{K}$ & Thermal conductivity & $4 \mathrm{~W}^{-1} \mathrm{~K}^{-1}$ \\
\hline k & Thermal diffsivity & $10^{-6} \mathrm{~m}^{2} \mathrm{~s}^{-1}$ \\
\hline$\eta$ & Dynamic viscosity & $10^{21} \mathrm{~Pa} \mathrm{~s}$ \\
\hline $\begin{array}{l}Q \\
v_{m}\end{array}$ & $\begin{array}{l}\text { Total heat flux } \\
\text { Mantle volume }\end{array}$ & $4.30 \times 10^{13} \mathrm{~W}$ \\
\hline & $\begin{array}{l}\text { Whole mantle } \\
\text { Upper mantle }\end{array}$ & $\begin{array}{l}9.06 \times 10^{20} \mathrm{~m}^{3} \\
3.07 \times 10^{20} \mathrm{~m}^{3}\end{array}$ \\
\hline$\dot{A}_{p}$ & $\begin{array}{l}\text { Present Areal } \\
\text { plate velocity }\end{array}$ & $3 \mathrm{~km}^{2} \mathrm{yr}^{-1}$ \\
\hline $\mathrm{U}_{\mathrm{p}}$ & $\begin{array}{l}\text { Present plate } \\
\text { velocity }\end{array}$ & $0.05 \mathrm{~m} \mathrm{yr}^{-1}$ \\
\hline $\mathrm{T}_{\mathrm{p}}$ & $\begin{array}{l}\text { Present characteristic } \\
\text { temperature }\end{array}$ & $1600 \mathrm{~K}$ \\
\hline \multicolumn{3}{|c|}{ Derived Quantities } \\
\hline $\begin{array}{l}\mathrm{Ra}_{\mathrm{q}} \\
\mathrm{Ra} \mathrm{T} \\
\mathrm{Pe} \\
\mathrm{Pe}\end{array}$ & $\begin{array}{l}\text { Whole mantle } \\
\text { Upper mantle } \\
\text { Whole mantle } \\
\text { Upper mantle }\end{array}$ & $\begin{array}{l}3.4 \times 10^{9} \\
6.6 \times 10^{5} \\
5100 \\
1200\end{array}$ \\
\hline
\end{tabular}

where $u_{x}$ and $u_{y}$ are the dimensionless horizontal and vertical velocities. $U^{u}(x, t)$ is a function specifying the variation of horizontal velocity on the top surface and is a function of time. $U^{2}(x, t)$ is referred throughout this paper as the plate evolution model. Most of these boundary conditions are commonly used in mantle convection models [cf. McKenzie et al., 1974]. However, the application of the top velocity boundary condition is not very common, and a detailed account and justification is given elsewhere [Davies, 1986].

\section{Force Scaling and Choice of Rayleigh Number}

The Rayleigh number for the mantle, especially for the whole-mantle convection scenario, is large (Table 1) and would require very fine grid spacings to resolve the thermal boundary layers. Low values of Ra (about $10^{5}$ ) were employed, first, to avoid excessive computation times, because a fairly coarse grid spacing (1/16) could be used. A more fundamental reason for choosing a low Ra, however, was to suppress small-scale instabilities of the thermal boundary layers. Because the viscosity is uniform in the models, realistic Ra's lead to the artificial instability of the top boundary layer; in the mantle this instability is strongly suppressed because of the high viscosity of the lithosphere [Yuen et al:. 1981]. On the other hand, the instability of the lower boundary is enhanced, if there is some bottom heating into a medium with temperature dependent viscosity [Yuen and Peltier, 1980]. Because the calculations presented here were intended to study the effect of only the large scale flow associated with plates, these small-scale instabilities, which start to form at $\mathrm{Ra}>10^{6}$ in a constant viscosity fluid [McKenzie et al., 1974], must be inhibited. Therefore a Ra of $10^{5}$ was used for most calculations.

Since the primary goal of this study is to better understand the effects of convective flow, of whatever scale, on mixing, the neglect of secondary scales of flow is a justifiable place to start. Beyond this, however, we believe that the role of any secondary scales in mantle convection may be minor, so that the present results could be of direct relevance to the mantle. Space does not permit a full discussion of this somewhat contentious topic (some aspects are discussed by Davies [1980a] and O'Connell and Hager [1980]). For the moment, our views will simply be summarized as follows. While some small-scale flow in the mantle may be superimposed on the large-scale flow being modeled here, it is clear that the large-scale flow accounts for most of the heat and mass flux in the mantle. In addition, the evidence for small-scale upper mantle cells is equivocal, while it is likely that narrow plumes of deep origin, for which the evidence is clearer, would have a smaller effect on mixing than more normal convective flow structure [Loper, 1985].

Because of the reduction of $R a, P e$ must be scaled to maintain the same ratio of boundary driven to buoyancy driven forces in the model as they are in the mantle. They scale as [Turcotte and Oxburgh, 1967; Davies, 1986]

$$
P e=B^{\prime} R_{T}^{2 / 3}=B R a_{q}^{1 / 2}
$$

where $\beta^{\prime}$ and $\beta$ are constants. The parameters are evaluated in Table 1. With a Ra of 3.4 $x 10^{9}$ for the whole mantle and a Pe of 5100, this gives a $\beta=0.087$. If $\mathrm{Ra}_{\mathrm{q}}=10^{5}$, then $\mathrm{Pe}$ $=50$. Because we used an upper limit on the internal heat production rate, $\mathrm{Ra}_{\mathrm{q}}$ is accordingly an upper limit, and therefore $\mathrm{Pe}$ may be underestimated. To account for the uncertainty, we will vary $P e$ between 20 and 100 , while Raq $=10^{5}$. For one case applicable to the upper mantle scenario, we employed $\mathrm{Ra}_{\mathrm{T}}=2 \times 10^{4}$ and $\mathrm{Pe}=200$.

\section{Passive Tracers}

During the plate evolution, passive tracers are introduced at the trench (i.e., where velocity segments are converging). A new tracer starts at each time step and is placed a distance 0.02 of the box depth below the margin. At each successive time step the position of the tracer is updated by a predictor-corrector method with accuracy $O\left(\Delta t^{2}\right)$, where $\Delta t$ is the time step [Conte and de Boor, 1972]. For steady flow we found an error $O\left(10^{-3} \mathrm{D}\right)$ in position, where $D$ is the box depth, after a tracer traveled around a closed streamline. The velocity is calculated from the stream function, which is defined in (9).

At the plate margins, velocity jumps are averaged over five grids to reduce the numerical inaccuracy in calculating the flow [see Davies, 
TABLE 2. Summary of Numerical Calculations

\begin{tabular}{|c|c|c|c|c|c|c|c|c|c|c|}
\hline Case & $\begin{array}{l}\text { Plate } \\
\text { Model* } \\
\text { Fig. } 1\end{array}$ & $\mathrm{Ra}$ & $\mathrm{Pe}$ & $d_{s}$ & $f^{\prime} t_{t}$ & $t_{r} / t_{t}$ & $\lambda_{m}^{-1 / t_{t}}$ & $t_{r} / t_{f}$ & Number & $\begin{array}{l}\text { Number } \\
\text { Sampled }\end{array}$ \\
\hline \multicolumn{11}{|c|}{ Periodic Plate Models } \\
\hline $\begin{array}{l}1 \\
2 \\
3 \\
4 \\
5\end{array}$ & $\begin{array}{l}a \\
a \\
b \\
b \\
a\end{array}$ & $\begin{array}{c}105 \\
105 \\
105 \\
105 \\
2 \times 10^{4}\end{array}$ & $\begin{array}{r}100 \\
50 \\
100 \\
20 \\
200\end{array}$ & $\begin{array}{l}0.05 \\
0.05 \\
0.05 \\
0.05 \\
0.15\end{array}$ & $\begin{array}{l}80 \\
80 \\
80 \\
80 \\
27\end{array}$ & $\begin{array}{r}70 \\
67 \\
127 \\
79 \\
33\end{array}$ & $\begin{array}{r}75 \\
80 \\
164 \\
85 \\
34\end{array}$ & $\begin{array}{l}0.9 \\
0.8 \\
1.6 \\
1.0 \\
1.2\end{array}$ & $\begin{array}{l}250 \\
250 \\
200 \\
300 \\
200\end{array}$ & $\begin{array}{l}250 \\
250 \\
198 \\
300 \\
200\end{array}$ \\
\hline \multicolumn{11}{|c|}{ Nonperiodic Plate Models } \\
\hline $\begin{array}{l}6 \\
7\end{array}$ & $\begin{array}{l}c \\
c\end{array}$ & $\begin{array}{l}105 \\
105\end{array}$ & $\begin{array}{r}100 \\
50\end{array}$ & $\begin{array}{l}0.05 \\
0.05\end{array}$ & $\begin{array}{l}80 \\
80\end{array}$ & & 97 & & $\begin{array}{r}650 \\
4000\end{array}$ & $\begin{array}{r}416 \\
1571\end{array}$ \\
\hline
\end{tabular}

* Plate model c not shown; see text.

1986]. Therefore the streamlines were less sharp at margins than they should be and the tracers are artificially slowed when traversing this area. The sampling zone is accordingly placed midway between the diverging and converging margin. This is a valid procedure because it is the cycling of material through the crust/lithosphere (i.e., the top thermal boundary layer of the flow) we wish to measure, and the lithosphere is the top part of the mantle flow. When a tracer passes through a square with sides $d_{s}$ directly under the sampling point, it is removed from the flow. The time each tracer spends in the box is recorded. If the length scale of melting beneath ridges (sampling scale) is of the order of $100 \mathrm{~km}$, then for whole-mantle convection, $\mathrm{d}_{\mathrm{s}}=0.05$, and for convection confined to the upper mantle, $d_{s}=0.15$.

\section{Mean Residence Time and Flux Time}

The mean residence time, $t_{r}$, is defined as the average time tracers remain in the box. Because the tracers are introduced into the flow in a way that simulates subduction of sediment/crust/depleted lithosphere and removed in a way that simulates incorporation into oceanic lithosphere, $t_{r}$ will be analogous to the mean reprocessing age $\langle\tau\rangle$ used in a later section. In cyclic models (see later), only tracers introduced during one cycle need be considered in the calculation of $t_{r}$.

A quantity that will become relevant later is the flux time, $t_{f}$, which is the time for an area equivalent to the box area to flux through the sample region:

$$
t_{f}=\frac{S}{d_{s} u_{b}}=\frac{S R a}{d_{s} P e}
$$

where $S$ is the dimensionless area of the box, $d_{s} u_{b}$ is the dimensionless flux through the sample region, $u_{b}$ is the imposed boundary velocity, and $d_{s}$ is the sample depth. If the flux time, $t_{f}$, is scaled by the transit time $(7)$, then

$$
\frac{t_{f}}{t_{t}}=\frac{s}{d_{s}}
$$

where $t_{t}$ is the transit time defined in terms of the boundary velocity. In the models, the ratio of the flux time to the transit time (12) is 80 for whole-mantle values and 27 for upper mantle values, where the dimensionless area of the convection box, $S$, is 4 and the $d_{S}$ were given above.

Calculation of the Strain of Subducted Fluid Elements

In order to understand the deformation associated with the subducted tracers, in some models fluid elements defined by four tracers on the corners of squares were introduced below the trench. Three concentric squares of width $\varepsilon_{0} \quad(0.005$, 0.025 , and 0.05 ) were employed; with such small $\varepsilon_{0}$, the size of the finite difference grid was doubled to 32 mesh points in depth in order to more accurately advect the tracers. The strains, $\delta$, of the elements are characterized by the average length of the two diagonals normal ized by the initial value $\left(\sqrt{2} \varepsilon_{0}\right)$. One new element is introduced at each time step, and after each tracer was in the flow a set time, its strain was recorded. A distribution of fraction of tracers versus strain, $f(\delta)$, then exists at this set time. An analogous distribution was calculated numerically when the tracers defining the four corners have positions uniformly random in each direction; this distribution is denoted $r(\delta)$ and is meant to represent the state when the fluid elements are thoroughly mixed. The following function is defined:

$$
\Gamma\left(\delta^{*}\right)=\int_{0}^{\delta^{*}}[f(\delta)-r(\delta)] d \delta^{\prime}
$$

$\Gamma\left(\delta^{*}\right)$ is the fraction of elements still with an average strain less than $\delta^{*}$ above what is expected for a well-mixed fluid. $\Gamma\left(\delta^{*}\right)$ can be calculated at different times, and the rate of deformation and the lifetime of subducted elements can be estimated. These results are found to be independent of the choice of $\delta^{*}$. $\delta^{*}$ was chosen to be five because subducted crust, for example, sheared out by a factor of 5 still 

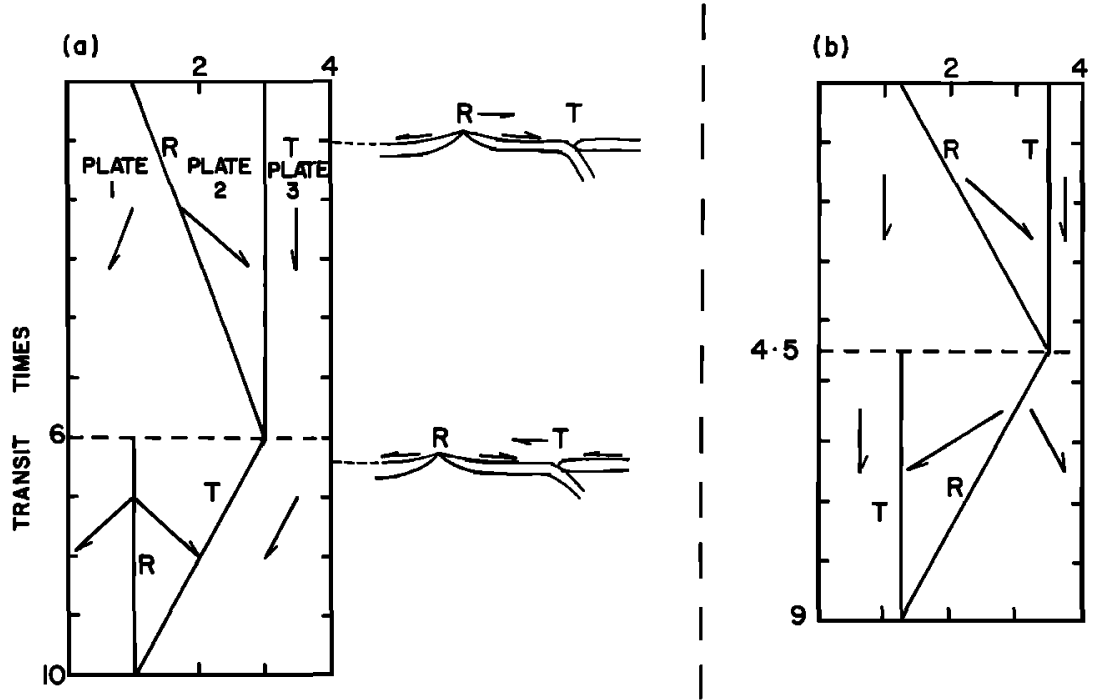

Fig. 1. Schematics of idealized plate evolutionary models used as top velocity boundary conditions for convection calculations. The plots are described in detail in the text. Distance across the top of the box is denoted horizontally, and the time (scaled by the transit time) vertically. Ridges are labeled "R" and trenches "T;" the arrows denote the direction and speed of plate motion. For Figure 1a the plate tectonic configuration is clarified by two sketches of to the right.

presumably would have significance in terms of generating an isotopic signature.

\section{Mixing in a Convective Flow Constrained by Plate Kinematics}

For the first fully dynamic convection calculations presented, an important simplification has been adopted: the plate evolution models (1.e., velocity boundary conditions: $U \mathrm{u}(x, t)$ equation (8)) are cyclic in time; this simplification was only employed, as we shall see, to reduce the numerical computations. Nevertheless, both the kinematics of plate motion and the introduction of tracers below the implicit trench are still basic features of the calculation. In the following section, however, we will deronstrate that the major conclusions to be drawn are, in fact, independent of this simplification. The first six calculations, which employed cyclic boundary conditions ( Table 2), display many common features and are best understood by considering the results of just one case (case 1) in detail.

Through both this section and the next, no mention will be made of the dimensional time scales to which different mixing features correspond. This will require a number of assumptions (some of unknown certainty), and it is best to divorce the discussion of basic fluid dynamics from mantle time scales. A separate section, scaling to the Mantle, will follow.

\section{Plate Model and Fluid Flow}

Case 1 has $\mathrm{Ra}=105, P e=10^{2}$, and internal heating. The relatively high $P e$ may give it greater boundary force than expected from wholemantle parameters. The higher $\mathrm{Pe}$ was chosen primarily because it has essentially the same effect on flow structure as does a high viscosity lid at this value of Ra [Davies, 1984b]. However, we shall later demonstrate that the conclusions are independent of this choice.

The plate model imposed on the convecting region is shown schematically in Figure 1a. In this flgure, distance across the box is represented horizontally, and the progression of time (in transit times) vertically. The sketches to the right of the box are intended to clarify the plate tectonic configuration at two instants. Solid lines are drawn between plate margins; a stationary margin plots vertically, for example, the trench (labeled "T"), but the ridge (labeled " $R$ ") Inigrates to the right. During the first stage, a symmetrically spreading ridge starts at $x=1$, migrates to the right, and reaches the trench at time 6 . A new trench forms at the collision point, migrates to the left until it coalesces with the ridge. The orientation
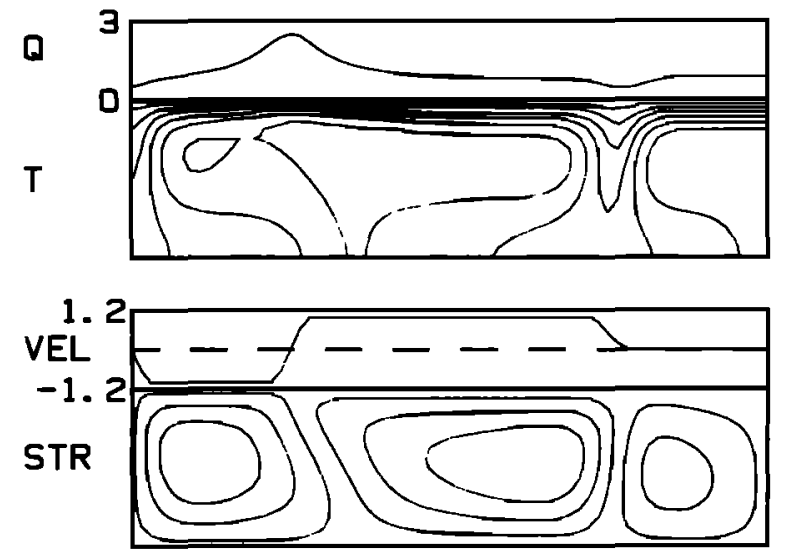

Fig. 2. Details of initial state of case 1 with $\mathrm{Ra}_{\mathrm{q}}=10^{5}, \mathrm{Pe}=100$ and internal heating. Quantities are the top heat flux (Q), temperature (T), top horizontal velocity (VEL, positive to the right), and stream function (STR). 

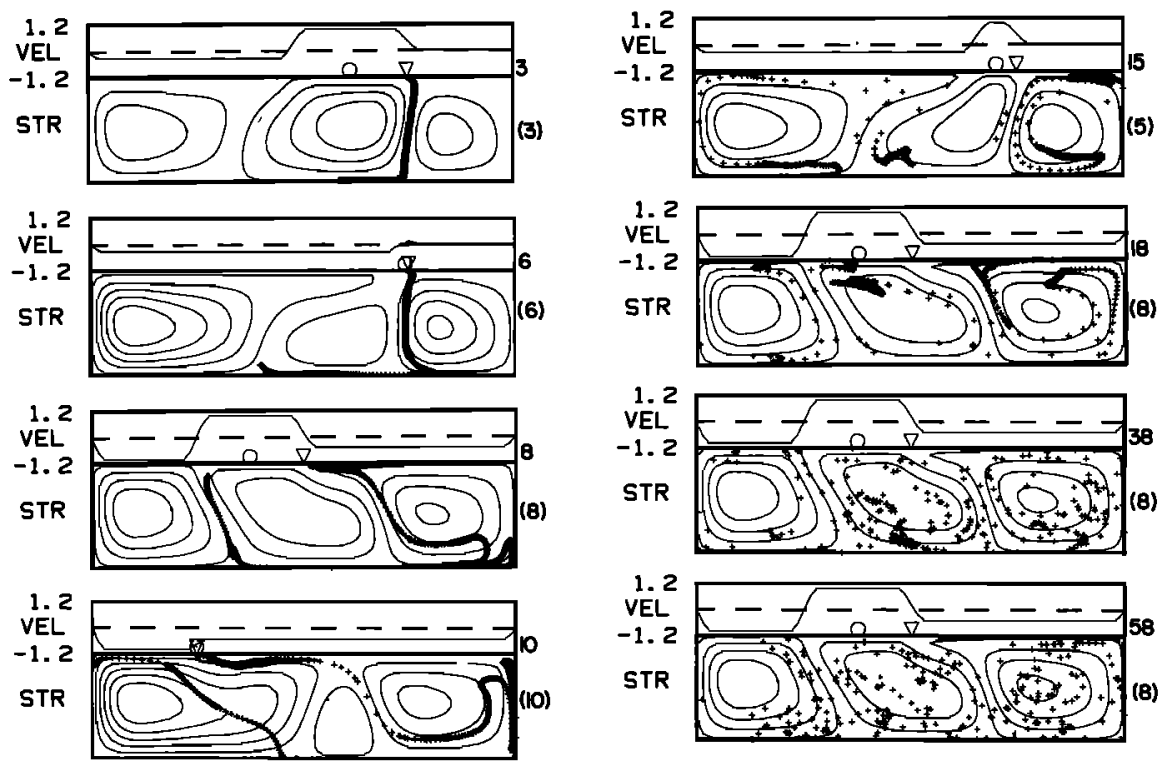

Fig. 3. Streamlines and tracer positions for case 1 at eight instants. On top of each box is the schematic of the velocity boundary condition. The circles, midway between the trench and ridge, denote the location of tracer sampling. The triangles denote the location of the implicit trench, where the tracers are injected into the flow. The values to the right of each frame are the total time, and in parentheses the phase in the plate evolution model (Figure 1a), both normalized by the transit time.

of the arrows shows the speed and direction of plate motion. The dashed line indicates plate rearrangement with a new sequence below the 1 ine. When time 10 is reached, the plate sequence repeats, starting again at time zero. This model is idealized but simulates the uniform velocity across plates, the symmetric flow at ridges, the asymmetric flow at trenches, and the migration of ridges and trenches.

This kinematic plate model forms the boundary condition for case 1 . To provide a reproducible starting state, the margins were inltially held stationary until the convecting region thermally reached an approximate steady state. In Figure 2 the details of this initial state are shown; on top, $Q$ is the heat flux emerging from the top of the box and shows a maximum over the region of upwelling. In the box labeled $T$ are the isotherms and show the thick thermal boundary layer on the top of the fluid and the isothermal interior of the upwelling region. The box labeled VEL is the imposed horizontal surface velocity (positive to the right), and STR are contours of the stream function. More details of these aspects of the calculations are contained in Davies [1986]. Next, the plate model (Figure 1a) was imposed on the convecting region. The calculation was cycled through the plate model of Figure la three times. The temperature and velocity fields then no longer changed significantly from cycle to cycle. Convergence to a cyclic velocity field resulted in a large decrease in computation time because the same sequence of stream function arrays could be used successively to advect the tracers.

\section{Qualitative Mixing Behavior}

In Figure 3, elght instants in the mixing model are shown with the tracers plotted on the streamline fields. The values labeling each frame to the right are the total time and, in parentheses, the phase of the plate model of Figure 1a, both normalized by the transit time. The tracers are introduced below the triangles, which locate the implicit trench. Initially, the tracers are positioned on the outer edge of the center cell, as shown at time 3. This pattern extends out to about time 5 , whereupon, because the center plate is being consumed between a ridge and a trench, the center cell shrinks, while the right cell grows. This causes the tracers to be swept over to the right cell, as shown at time 6 , when the ridge and trench have just coalesced. Notice at time 6 how the tracers are pinched between the right cell and the bottom of the box. At time 6 the plates rearrange, as shown in $F$ igure $1 a$, and a new stationary ridge forms on the left and a new trench on the right. The situation at time 8 is shown after the new trench has migrated to the left; the tracers are progressively left behind as the trench migrates rapidly to the left as shown at times 8 and 10 . The fold or clump of tracers forming on the bottom at time 6 can be followed as it swings around the right cell at times 8 and 10 . This fold seems to maintain its intensity. Notice the formation of the broad fold interior to the first fold at time 8 and how it seems to diminish in intensity, at least from times 8 to 10 , as it is sheared out. After time 10 (one cycle), no more tracers were introduced. The strings get torn apart as the flow goes through another cycle of plate evolution as shown at times 15 and 18 . Nonetheless, there is a strong tendency for clumps of tracers to persist, as clearly seen at time 18, and there are even clumps at time 38 . By time 58 , however, no dense clumps can be recognized, al though there is still considerable nonrandom 


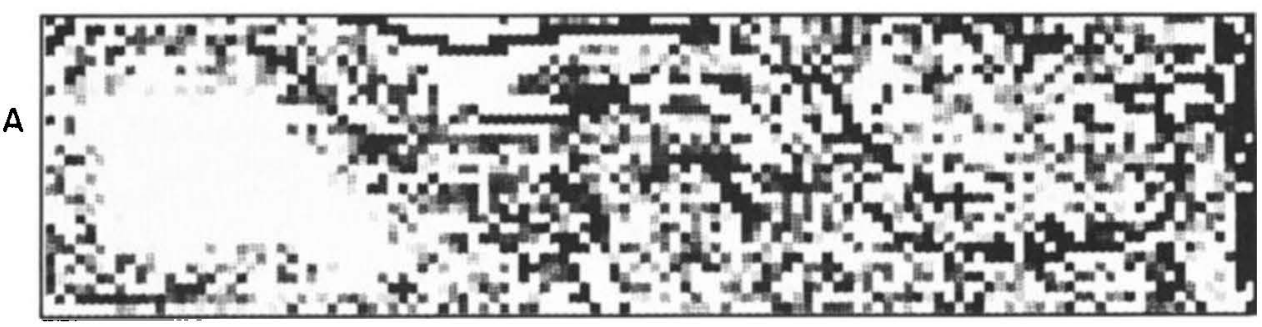

120

AGE

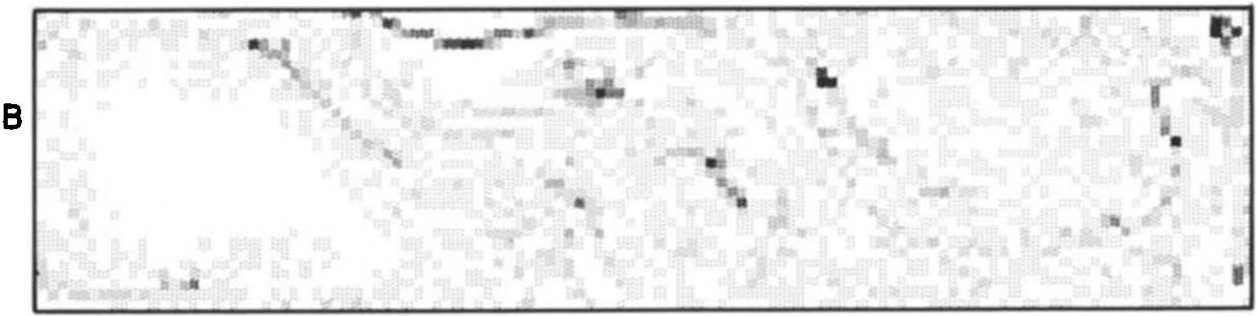

40

AGE

Fig. 4. Composite images of the tracers introduced during the first period of plate evolution for case 1, seen at phase 10 in the periodic plate model of Figure 1a. The convecting region was divided into small squares of sides 1/30 of the box depth, and tracers were sampled in two different ways. The sample size implicitly represents a $100-\mathrm{km}$ sampling size in the whole mantle convection scenario (3000-km depth). As discussed in the text, the sampling was performed two ways in order to account for the uncertainty in the way the heterogeneous mantle is sampled beneath ridges. (a) Unwelghted average of the tracers within each sample square; if no tracers ocurred in the square, then the age was set to the maximum: 120 transit times. (b) Weighted average of the tracers. We assumed each tracer had an area equivalent to crust of 6-km thickness and a length equal to the time step times the subduction velocity. Since the sample width is $1 / 30,28$ tracers would "fit" into the sample square. The average age of the sample region is the sum of each tracer (each of weight one) plus the background (age 120) times a weight of 28 minus the number of tracers in the square, all divided by 28 .

heterogeneity evident in the distribution of tracers.

Because this model is periodic in time, tracer positions and ages from consecutive periods can be added together to form a composite. The tracer position and ages were recorded at the end of the plate evolution model for 12 consecutive periods. Then the ages were averaged over small squares (sides 1/30) and plotted with an intensity proportional to the age of the square. The result is shown in Figure $4 a$, which is at the end of the second stage (plate phase 10 transit times). The darker the shading, the younger is the sampling square. If no tracers were found in the box, then the age was set to 120 , so in actuality those positions with the lightest shading are older than 120 transit times. This type of plot shows well that clumps of tracers tend to persist out to transit time 40. An important feature clearly seen in Figure $4 a$, but not at all obvious in Figure 3 , is that the convection cell on the left has remained essentially isolated from the tracers. The tracers are only slowly migrating into the cell. The significance of this plot is discussed below.

\section{Dynamic Persistence of Clumps of Tracers}

By focusing in on a group of tracers, we can determine the cause for the persistence of clumps. Shown in Figure 5 is a group of tracers from case 1; these are the tracers that formed the kink at the bottom of the cell at time 6 (Figure 3). This group is followed from time 6 to 10 , and the streamlines are the same as those in Figure 3. One tracer on the interior of the fold limb is marked with a circle; notice how this marker tracer passes from the interior fold limb (time 6) to the fold apex (time 8 ) and finally to the exterior limb (time 10) as the group of tracers moves around the convection cell. The fold apex seems to maintain its intensity as new tracers flux through it. The cause of this is simple: the angular velocity is greater toward the center of the convection cell, and this causes a particular tracer, interior to a second tracer, to approach the first tracer and then pass 1t. The high concentration of tracers is in relative motion to the tracers themselves. This results in the persistence of a chemical anomaly. The behavior of these 

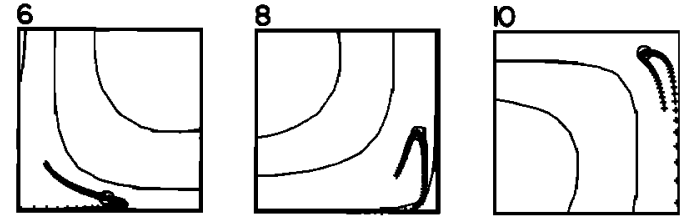

Fig. 5. Detail of a string of tracers making a circuit of the right convection cell in Figure 3. The times labeling each frame are the same as those in Figure 3 and so are the streamlines. One tracer has been marked with a circle, and this clearly demonstrates how tracers flux through the fold apex. This shearing of the string results in a persistent high-density concentration of passive tracers.

dynamic folds will be demonstrated in other kinds of flow below. This behavior in fact approximates the "unmixing" phenomenon that occurs when high-viscosity flow, in the absence of diffusion, is reversed [Heller, 1960], and it occurs here because the tracer strings have been transferred from one cell to a counterrotating cell.

It is important to discuss the persistence of tracer clumps in light of what we think they actually represent: oceanic crust and sediment that have distinct chemical characteristics in comparison with the average mantle. The anomalous chemistry of the oceanic crust and sediments resul ts in different mineral assemblages compared with ambient mantle at depth, and this could result in the subducted material having intrinsic buoyancy [Ringwood, 1982]. Because the dynamic folds concentrate the tracers, any intrinsic density contrast would be enhanced. A clump of "light" tracers would tend to rise, while a clump of "heavy" tracers would tend to sink. Such calculations are beyond the scope of this paper, but dynamic folding in conjunction with tracers having intrinsic density could clearly be important and could lead to the segregation of tracers either to the bottom or top, depending on the sign of the intrinsic density.

Since the chemical characteristics of the subducted material also include a high concentration of the heat producing elements $U, T h$, and $K$ [Fyfe, 1979], the chemical anomaly could also give rise to a thermal anomaly within the mantle. Estimating the magnitude of any thermal anomaly is difficult because of the relative motion of the anomaly with respect to the tracers. This phenomenon is important because some hot spots (and thus perhaps diapiric instabilities) may come from recycled crustal material [Kurz, et al., 1982; Davies, 1984a] and will have to be addressed with more elaborate calculations, which are beyond the scope of this paper.

Strain of Fluid Elements Associated With the Tracers

A feature not apparent from the results presented so $f a r$ is the deformation experienced by the subducted material. A significant result of McKenzie [1979] is that the strain experienced by finite fluid elements in convection is rapid; taking shearing at face value leads one to suspect the mantle could become well mixed on a time scale of $100 \mathrm{~m} . \mathrm{y}$. [McKenzie, 1979]. For case 1 the strain for three initial sizes of fluid elements, which were introduced below the trench, are determined at transit times 10, 20, and 30. In Figure 6 the fraction of elements with a strain of $\delta^{*}=5$ or less is shown $\left(\ln \Gamma\left(\delta^{*}\right)\right)$. The nondimensional scale of oceanic crust $(6$ $\mathrm{km}$ ) in the whole-mantle convection scenario is 0.002 . For each of the three initial sizes $\varepsilon_{0}$ $(0.005,0.025,0.05)$, the fraction still with minimal deformation decays exponentially with time and, within the accuracy of the calculations, the rate of decay is independent of $\varepsilon_{0}$. It must be emphasized that the range of $\varepsilon_{0}$ is small (1 order of magnitude), and a larger interval could give a rate of decay that depends on $\varepsilon_{0}$. Assuming $\Gamma\left(\delta^{*}\right)$ decays exponentially, the half-lives are approximately seven transit times for each $\varepsilon_{0}$. The relationship of this straining to the strain in single steady cells, as calculated by McKenzie [1979], is not easy to quantify (see Appendix $C$ ). However, there is no obvious inconsistency with the persistence of clumps of tracers that is caused by unmixing.

Furthermore, there is a rough correlation between clumps of tracers and tracers with minimal deformation; in other words, the strains of the fluid elements within clumps are generally small. For example, at time 10 in Figure 3 , the elements within the clump in the top right corner are among those with the smallest deformation

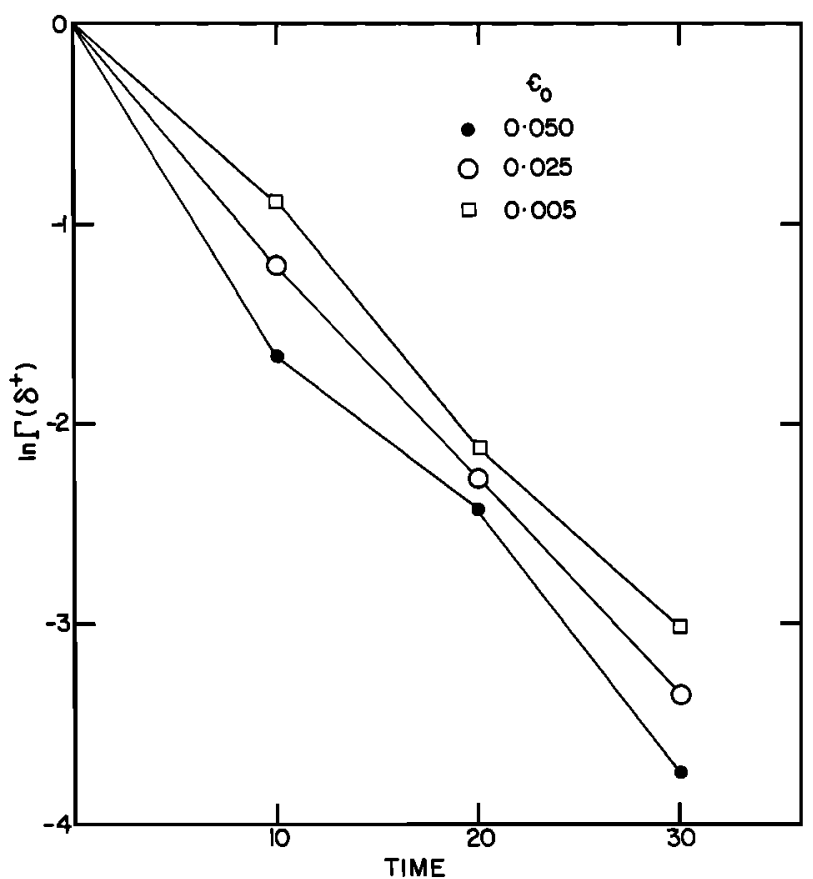

Fig. 6. The log of the fraction of fluid elements that have strains of five or less above what is expected for a thoroughly mixed fluid, $\Gamma\left(\delta^{*}\right)$, defined in (13), at three times and for three initial sizes of fluid elements, $\varepsilon_{0}$. The decay can be approximated with a half-life of seven transit times for each $\varepsilon_{O}$. These calculations were carried out on a grid with $32 \times 128$ mesh points. 
at this instant, while the strain for the elements within the string stretching across the left cell are among the highest at this instant.

Relation of Figure 4 to Sampling by Ridge Magmatism

The formation of midocean ridge basalts by magmatic fractionation may sample and mix the isotopic ratios of the mantle in ways that fall between two extremes. At one extreme, some small mantle segments may have lower solidi for a given pressure and hence may melt more extensively and contribute more to the final average than other small segments with higher solidi [see, for example, Sleep, 1984]. Segments that are volatile and incompatible element enriched (like recycled crustal material) would have such an effect and could dominate the final isotopic average of the melt. At the other extreme, there may be partial melting through some volume, and each small segment within this volume may equally melt and equally contribute species to the final average melt.

In order to account for the uncertainty in the way magmatism may sample the heterogeneous mantle, we constructed plots that are intended to mimic these two end-member hypotheses. Figure $4 a$ was produced by an unweighted average of the age of tracers in the sample areas and so mimics the former hypothes1s: preferential sampling of recycled material. Figure $4 \mathrm{~b}$ was intended to mimic the latter hypothesis: the simple averaging of material through the sample region. The details on the construction of these plots are given in the figure caption. The fact that many scales of variation occur in both Figure $4 a$ and $4 b$ demonstrates that analogous isotopic variations can exist in a convecting fluid.

Because subducted material has such a high concentration of the heat-producing elements $U$, Th, and $K$ [see, for example, Fyfe, 1979], the chemical anomaly associated with the segregation of the left cell in Figure $4 \mathrm{a}$ would represent a cell with less internal heat production in comparison to the rest of the box. Such a distribution is stable [Honda, 1984] because the heat production is located on the exterior of the cell, where the heat is easily transported out of the box. This configuration may actually tend to enhance the stability of the cell. The stability of the cell originally caused such a heterogeneous distribution of chemical tracers, but now the chemical tracers may actually enhance that stability even further and cause an even grosser heterogeneous distribution of chemical tracers. Such a possibility deserves further study.

\section{Residence Times}

The average residence time for the tracers was calculated directly by running the calculation for over 400 transit times with a reduced number of tracers, 250, until all of the tracers were finally sampled. In Table 2 this average is normalized by the transit time $t_{t}\left(t_{r} / t_{t}\right)$ and is equal to 70 . This value compares favorably to the flux time $\left(t_{f} / t_{t}\right)$, which is 80 ; in other words, the average residence time can be predicted from the boundary conditions of the flow. These times are discussed further in the section Random Sampling Model.

Additional Convective Mixing Calculations

Periodic Plate Models

Four other cases were carried out with periodic plate evolution, like case 1 just described: cases 2 to 5, Table 2. Using both plate model "a" and also an additional model "b" of Figure 1 , the $P e$ was varied between 20 and 100 , while $\mathrm{Ra}=10^{5}$ in three cases (cases 2 - 4), while also employing internal heating. There were no significant differences in the way the tracers mixed, including the existence of dynamic folds, which persisted out to about 40 transit times, on average.

One of the model runs, case 5, had parameters more appropriate to the upper mantle convection scenario: $\quad R a_{T}=2 \times 10^{4}, P e=200, d_{s}=0.15$, and bottom heating. Qualitatively, the mixing phenomena were essentially the same as the other model runs. This case may not be a very good analog to upper mantle convection, because any "plate" in this model was never greater than 2 times the box depth, whereas the aspect ratio for upper mantle cells could be as large as 10, and this might limit the applicability of the model to the mantle.

In each case the residence time was compared with the flux time, $t_{r} / t_{f}$ (Table 2). The $t_{r} / t_{f}$ were in the range 0.8 and 1.6 with most falling near unity and only one departing significantly. The significance of these results will become apparent in the section Random Sampling Model.

\section{Nonperiodic Plate Models}

An important criticism of the flows just studied is that they have a high degree of order, whereas from our understanding of plate kinematics, we may expect that the associated large-scale flow to perhaps have less regularity: plate sizes vary widely (from about 1000 to 10,000 $\mathrm{km})$, and the velocities of both plates and plate margins also vary widely. The purpose of this section is to test this assumption by using pseudorandom velocity boundary conditions.

This model is referred to as "c" in Table 2 and has 27 distinct stages of plate motion that were between 1 and 9 transit times in length. The number of plates during each stage was between two and five. Plate evolution included trench migrations and ridge migrations, both singly and in combination. However, there was only one source and one sink during each stage. The model is referred to as "pseudorandom" in the sense that, qualitatively, no repetitions or periodicities were incorporated a priori. A detailed description of the plate evolution model is available on request from the authors.

Case 6 has $\mathrm{Ra}=10^{5}$ and $\mathrm{Pe}=100 ; 650$ tracers were introduced over the first three plate stages (13 transit times). We found that dynamic folds occurred in the flows and that clumps of tracers persisted out to 40 transit times. Also significant is the lack of a large-scale anomaly like the one found in case 1, which resulted in the left cell being devoid of tracers (see Figures 3 and $4 \mathrm{a})$. The lack of this long length scale 

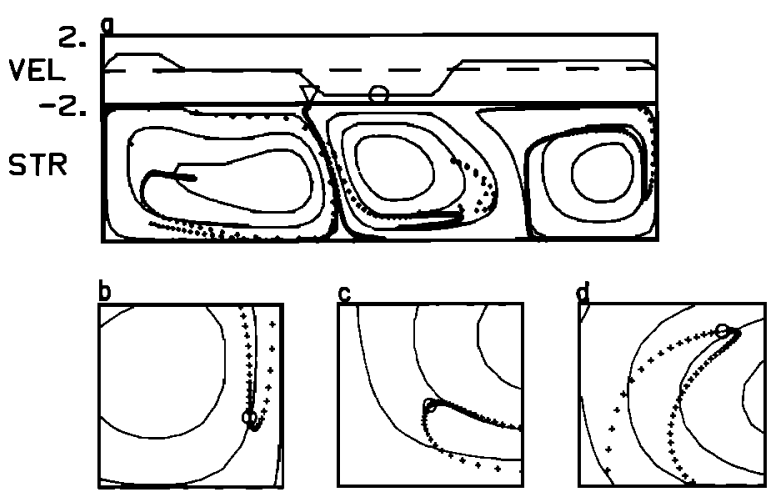

Fig. 7. Case 7 at transit time 43. The velocity boundary condition shows the location of a trench (triangle), which is stationary, and a ridge, which is migrating toward the left. The plate evolution model is pseudorandom in time. Only those tracers introduced during the previous 11 transit times have been plotted. The fold descending near the right side of the box is shown in detail in Figures $7 b-7 d$. One tracer is marked. This calculation clearly demonstrates that persistent dynamical folds are a robust feature of even models with pseudorandom plate evolution.

anomaly is ensured because no cell could persist for more than a few stages in this plate model. We also employed this plate model for case $7(\mathrm{Ra}=105$ and $\mathrm{Pe}=50)$. The tracers were introduced over the entire 100 transit times. In Figure $7 \mathrm{a}$, one instant is shown at time 43 when a ridge is migrating to the left toward a stationary trench, denoted by the triangle. For clarity, only the tracers introduced during the previous 11 transit times have been plotted. Notice two well-developed folds in the tracer strings: one in the center cell moving toward the region of upwelling under the ridge and the other in the downwelling limb of the right cell. The rightmost fold is shown in detail in Figures $7 \mathrm{~b}-7 \mathrm{~d}$. Figure $7 \mathrm{~b}$ is also at time 43 and is just an enlargement of a segment of Figure $7 \mathrm{a}$. One tracer on the interior limb of the fold is marked with a circle. This group of tracers is followed through the unsteady flow from time 43 to 44 (Figure $7 \mathrm{c}$ ) to 45 (Figure 7d). During this time, the marked tracer moves from the interior limb to the apex at time 44 and then moves out onto the outer limb of the fold; this clearly demonstrates that dynamic folds exist even in flows that are constrained by pseudorandom plate evolution.

\section{Mixing in Simple Analytic Flows}

Further insight into the mixing of tracers can be gained with simple kinematic flows prescribed by analytic stream functions that exhibit features displayed by the full solution of the governing equations. Both a wider range and a better controlled set of parameters can be employed. The principal features that need to be incorporated into these calculations are the growth and shrinkage of the large-scale circulation and the migration of the source of the chemical anomaly. This can be accomplished with two cells rotating in opposite directions (descending flow between them) and with tracers being introduced at a point source between the cells. A stream function for such a flow is

$$
\begin{aligned}
& \Psi=A(t) \sin \left\{\pi \frac{x}{X(t)}\right] \sin (\pi y) \quad x<x(t) \\
& \Psi=B(t) \sin \left[\pi \frac{x-X(t)}{w-X(t)}\right] \sin (\pi y) \quad x>X(t)
\end{aligned}
$$

In (14) the stream function, $\Psi$, is defined in (9). Similar equations have been used to approximate convection cells previously [Richter et al., 1982; 0lson et al., 1984]. In (14) the width of the box is $w$ (depth being unity), and the $x$ coordinate is positive to the right and $y$ positive upward. The boundary between the cells is $x(t)$. With the definition of the stream function in (9), (14) characterizes clockwise flow on the left and counterclockwise on the right; this gives downwelling at $x(t)$. In order that the vertical velocity be continuous at $x(t)$, it can be shown that the coefficients, $A$ and $B$, have the form

$$
\begin{gathered}
A(t)=C X(t) \\
B(t)=C[w-X(t)]
\end{gathered}
$$

The coefficient, $\mathrm{C}$, is the flow amplitude. The boundary between the cells oscillates as

$$
x(t)=w / 2[1+E \sin (\Omega t)]
$$

where $E$ is the margin amplitude and $\Omega$ is the margin frequency. The velocity field is easily found by differentiating (14) using the definition of $\psi$ in ( 9 ).

The tracer positions are integrated numerically from the analytic solution of the velocity field. The advection scheme was centered in time and space. A tracer accumulated an error $0\left(10^{-6}\right)$ during one circuit of a steady closed cell. A tracer is introduced at each time step with position $x=X(t), y=1-\delta y$ (where $\delta y$ is 0.02 ).

The average flow velocity is proportional to the flow amplitude, $C$, while the margin velocity is proportional to $\Omega \mathrm{E}$. Intuitively, increased margin amplitude and margin velocity, relative to the internal flow velocity, should increase the efficiency of mixing. This suggests that the form of mixing may best be studied as a function of the dimensionless ratio $\Omega E / C$. Because the margins between the lithospheric plates are on the order of the plate velocities, we expect an appropriate mantle $\Omega \mathrm{E} / \mathrm{C}$ near unity. However, for a thorough understanding, cases with $\Omega \mathrm{E} / \mathrm{C}$ both greater and less than unity were investi gated.

Two examples are shown in Figure 8 , and each frame is labeled by the time (left) and the phase of margin oscillation (right). The times quoted here can be approximately converted to transit times by multiplying by $\pi$. In each case, 150 tracers are introduced over a time 0.8 . The first example in $F$ igure 8 a has a margin amplitude, flow coefficient, and margin frequency, all set to unity $(\Omega \mathrm{E} / \mathrm{C}=1)$. As the margin moves to the right, as shown at times 0.4 and 
(a)
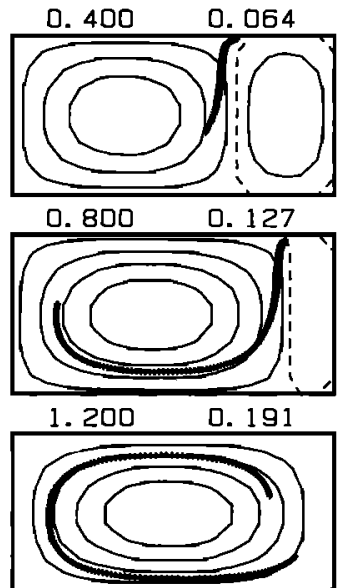

1.600

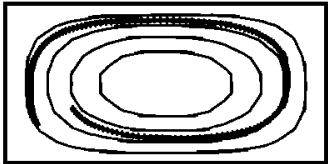

(b)

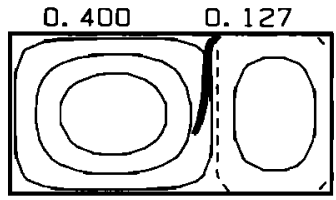

‥ 800

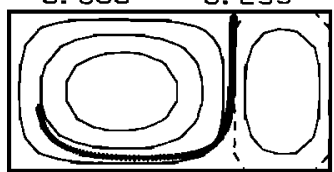

1. 200

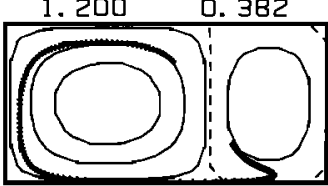

1. 600

0.509

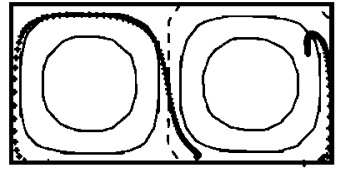

2. $000 \quad 0.318$

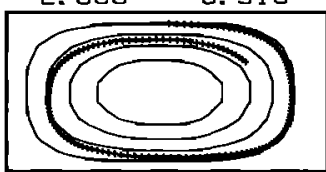

2. $400 \quad 0.382$

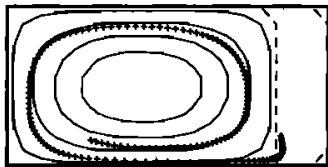

2. 800

0.446

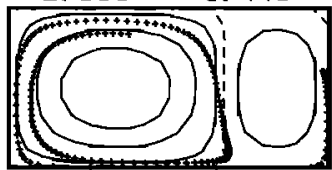

3. 200

0. 509

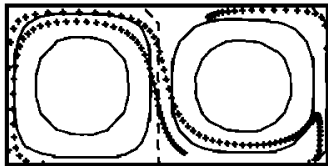

2. 000

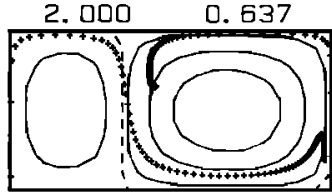

$\begin{array}{ll}\text { 2. } 400 & 0.764\end{array}$

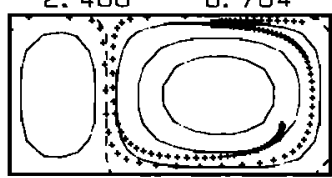

$\begin{array}{ll}2.800 & 0.891\end{array}$

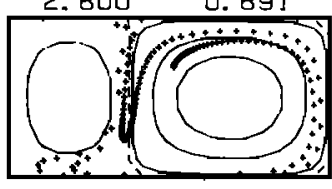

3. $200 \quad 0.019$

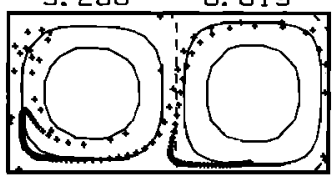

3.600 6.573

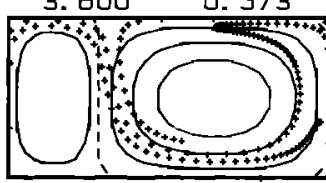

$\begin{array}{ll}4.000 & 0.637\end{array}$

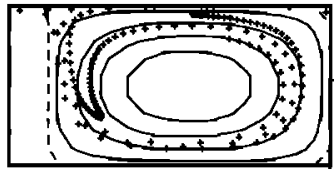

$4.400 \quad 0.700$

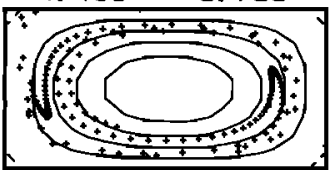

4. $800 \quad 0.764$
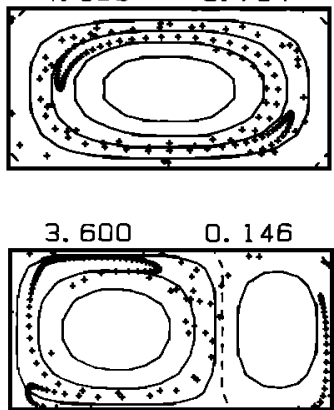

$4.000 \quad 0.273$

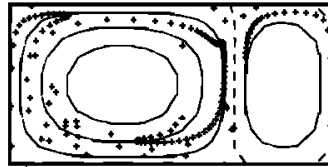

4. 400 0. 401

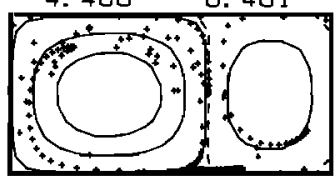

4. $800 \quad 0.528$

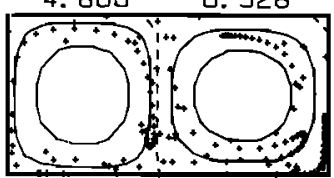

Fig. 8. Streamlines of the sinusoidal flows defined by (14) and tracers introduced on the margin between the two convection cells. (a) $E=1, \Omega=1$, and $C=1$. (b) $E=0.4$, $\Omega=2$, and $C=2$. The values labeling each frame are the time, left, and the phase of margin position, right. These times can be approximately converted to transit times by multiplying by $\pi$.

0.8 , the tracers are placed on streamlines progressively further from the center of the left cell. Because the angular velocities decrease from the center of the cell, this string of tracers will be progressively sheared. After time 1.6, the margin starts to move back toward the left, and at time 2.4 the margin passes over the string of tracers. Initially, the tracers passing over the margin seem to be more densely concentrated; however, this "hook" is quickly sheared out, as illustrated by following the group from 2.8 to 3.2 . At time 2.8 the margin passes over a second string of tracers. and another fold forms. From time 3.2 to 4.4 this fold makes a complete circuit of the right cell; notice that during this time the clump of tracers seems to maintain its "intensity." In other words, the number of tracers in the "clump" seems to remain constant. Close inspection of the fold reveals, like the folds found in the true convection flows, that the fold is dynamic.

A further case is shown in Figure $8 \mathrm{~b}$ with $E=0.4, C=1$, and $\Omega=2$. This example shows another dynamic fold that starts forming at time 1.6. At 2.8 the fold crosses the margin but is not destroyed. Rather, the direction of tracers fluxing through the fold reverses, and hence 


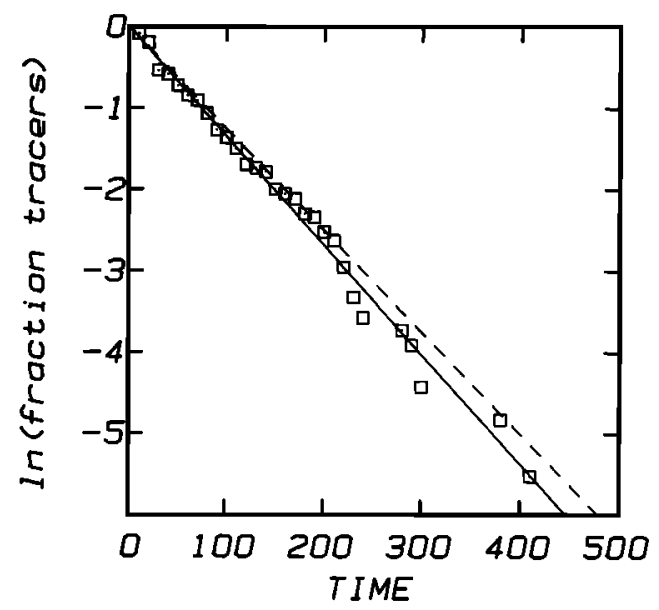

Fig. 9. Case 1. Ln of fraction of tracers remaining in the box as a function of transit time. The solid line is a least squares fit to the points, and the dashed line is the model predicted by the flux time (equations (11) and (18)). This clearly demonstrates that the number of tracers remaining in the box decays exponentially, and hence tracer sampling is random.

the lifetime of the anomaly is increased further; eventually the end of the string will flux through the fold apex, and the clump will cease to exist.

Cal culations have been made wi th margin amplitudes as small as 0.5 and with frequencies between 0.04 and 8 . The formation of persistent dynamic folds exists throughout this parameter range and is clearly a general phenomenon.

\section{Random Sampling Model}

In order to scale the residence times to the mantle, we show in this section that the residence times and the rate at which the tracers are sampled can be understood in terms of some rather elementary concepts. To assess how efficiently tracers are transferred from trench to $\mathrm{ridge}$, we will calculate the time expected in the special case of the random sampling of tracers and then compare it with the residence times calculated directly. Random sampling implies that the rate of sampling or the rate at which the total number of tracers remaining in the box, $\mathrm{N}(\mathrm{t})$, decreases is proportional to the total number in the box. Furthermore, random sampling implies that the rate of sampling should be proportional to the flux rate of fluid through the sampling region times the number of tracers per unit area:

$$
\frac{\partial N(t)}{\partial t}=-\lambda N(t)=-\left[\frac{u_{b} d s}{s}\right] N(t)
$$

where $\lambda$ is the tracer sampling decay constant. From (11), (17) implies $\lambda=1 / t_{f}$, under the assumption that the average velocity of fluid moving through the sampling region is about the same as the boundary velocity (plate velocity). The solution to (17) is

$$
N(t)=N_{0} e^{-\lambda t}
$$

where $\mathrm{N}_{0}$ is the number of tracers at time 0 . It can be shown from (18) that the mean age is $1 / \lambda$.

A sufficient condition to demonstrate random sampling is that the number remaining in the box decays exponentially. We will plot $\ln \left(\mathrm{N} / \mathrm{N}_{0}\right)$ versus transit time. If the measured values form a linear trend (i.e., exponential decay), then we have shown that the tracers are sampled randomly, and we calculate a slope, $\lambda_{m}$, and compare it with both $1 / t_{f}$ and $t_{r}$. It may be the case, however, that $t_{f} \neq 1 / \lambda_{m}$, because the imposed boundary velocity may not be exactly the same as the velocity of the tracers through the sample region, although it should be a good first approximation.

These tests and comparisons are carried out for the full convection calculations. Reproduced in Table 2 are the flux time normalized by the transit time $\left(t_{f} / t_{t}\right)$, the residence time normalized by the transit time $\left(t_{r} / t_{t}\right)$, the inverse of the slope of the tracer versus time relation normalized by the transit time $\left(\lambda_{m}^{\left.-1 / t_{t}\right)}\right.$, the number of tracers introduced into the flow, and the number of tracers sampled. For long time scales the random sampling model described by (17) holds very well as shown in Figure 9 for case 1. The open squares are the number of tracers in the box at the end of each period and are only plotted if tracers were sampled during the time interval. The dashed line is predicted from the flux time by (17) and has a slope $1 / t_{f}$. The solid $l$ ine is a linear regression of the points shown; 1 t has a slope of $\lambda_{m}\left(1 / \lambda_{m}\right.$ $=75$, normalized by the transit time) and a correlation coefficient, $r$, of -0.994 . Both lines give equally good fits to the numerical model results. The random sampling model even holds for transit times < 50 (Figure 9) despite the spatial heterogeneity of the source region (Figure 3). In summary, for case 1 , we find $t_{f} / t_{t}=80, \lambda_{m}{ }^{-1} / t_{t}=75$, and $t_{r} / t_{t}=70$, which is an internally consistent set of results: the tracers are sampled approximately randomly, and we can predict the residence time and the rate of sampling from the flux time.

When linear trends were $f$ it to the other cases, we found $r<-0.99$ (except for one, case 5. which had an $r=-0.976)$. This quantitatively demonstrates the good fit provided by the $r$ andom sampling model; in addition the residence time can be predicted by the flux time to within about $20 \%$.

Although there is an added complication because of the introduction of the tracers into the flow over a finite period of time, rather than at one instant; the effect is ignored to a good approximation, because the time to sample all the tracers is hundreds of transit times. In the following sections the random sampling model is exploited to scale the results to the mantle.

\section{Scaling to the Mantle}

The survival time for clumps of tracers and the mean residence times of tracers are scaled in this section to dimensional model times. Both upper mantle and whole-mantle convection are considered when making the scalings. Because the clumps of tracers are sheared out by the 
flow, clump survival time depends on the accumulated shear. The survival time will be a function of only velocity. Scaling of the residence time, however, depends on both velocity and the size of the sampling region(s). In the numerical model, the sampling region reduces to a single sampling depth; however we must consider the total length of ridges and the depth of sampling by magmatism when scaling to the mantle. The survival and residence times will both scale to a billion years or more. Since the rate of convection has decl ined appreciably over this time [McKenzie and Weiss, 1975; Burke et al., 1976], the decay of convection must be considered in such scalings. This effect is also explored here, with details given in Appendixes $A$ and $B$.

\section{Survival Time}

The survival time of clumps of tracers will first be scaled assuming constant velocity and hence constant transit time. At present, the average velocity of 11 thospheric plates is 5 $\mathrm{cm} / \mathrm{yr}$; this value was found by dividing the areal rate of plate generation $\left(3 \mathrm{~km}^{2} / \mathrm{yr}\right.$, Chase [1972]) by the length of ridges. With this velocity, the transit time for convection confined to the outer $700 \mathrm{~km}$ of the mantle is $14 \mathrm{m.y}$. and is $60 \mathrm{~m} . \mathrm{y}$. for convection extending throughout the whole-mantle. The survival times for the most persistent clumps of tracers were about 40 transit times; at present rates, the survival time scales to $2.4 \mathrm{~b} . \mathrm{y}$. for whole-mantle convection and $560 \mathrm{~m} . \mathrm{y}$. for upper mantle convection. In Appendix A, it is shown that when the more rapid convection rates of the past are accounted for, the survival times are reduced from 560 to about $470 \mathrm{~m} . \mathrm{y}$. and from 2.4 to about $1.4 \mathrm{~b} . \mathrm{y}$. for upper and whole-mantle convection, respectively.

In terms of the whole-mantle convection scenario, the persistence of chemical anomalies in these mixing calculations is in accord with the persistence of mantle chemical reservoirs for billions of years, even assuming the mantle was convecting much more vigorously in the past. Furthermore, the scaled results lend strong plausibility to the hypothesis that much of the isotopic and chemical heterogeneity of the mantle is in blobs that are entrained in convective flow [Davies, 1984a; $Z$ indler et al., 1984], a hypothesis hitherto thought kinematically unsound [cf. MoKenzie, 1979] (see also Appendix C).

\section{Residence Time}

Both plate velocities and total sampling volume must be considered in the scalings of residence times. In the scalings, we approximate the sampling of heterogeneities by a simple $r$ andom sampling model. The volumetric rate of mantle recycling (i.e., the fluxing of fractionated mantle through the oceanic crust and depleted lithosphere) is approximated as the product of the areal rate of plate generation, $\dot{A}$, and the depth over which partial melt is extracted, $\mathrm{d}_{\mathrm{m}}$; this depth is of the order of the depth of oceanic crust, $d_{o c}$, divided by the degree of partial melting, $\mathrm{F}$ :

$$
\dot{V}_{r}=d_{m} \dot{A}=\frac{1}{F} d_{o c} \dot{A}
$$

The reprocessing of mantle rocks over time leads to an age distribution, which is the fraction of mantle volume versus the age since last fractionation. In other words, at time $t$, the mantle is grouped into small volumes, $v(\tau, t) d \tau$, with ages between $\tau$ and $\tau+d \tau$; the volumes need not be continuous but may be dispersed throughout the mantle; the volumes must be large enough that their isotopic identity is retained. Applying the result of the numerical calculations, the parcels of the mantle are assumed to be sampled randomly below ridges. This means that the rate at which a mantle parcel of age $\tau$ is reset is proportional to the total volume of that age:

$$
\frac{\partial v(\tau, t)}{\partial t}=-\sigma v(\tau, t)
$$

where $\sigma$ is a positive quantity. A simple limiting case is obtained if $\sigma$ is constant. In this limit and with the boundary condition $v(t, t)$ $=\dot{V}_{r}$ (1.e.., the rate of recycling at any time $t$ is $\dot{V}_{r}$ and is constant in time) the solution to 20 is

$$
v(\tau, t)=\dot{V}_{r} e^{-\sigma \tau}
$$

If the mantle volume, $v_{m}$, remains constant in time, then

$$
\int_{0}^{t} v(\tau, t) d \tau^{\prime}=v_{m}
$$

From (22), we find $\sigma=\dot{V}_{r} / V_{m}$, so that constant $\dot{V}_{r}$ implies constant $\sigma$. This is the condition of the numerical models, where we found $\lambda=$ $1 / t_{f}$.

The mean age of mantle reprocessing is def ined as

$$
\langle\tau\rangle=\frac{1}{V_{m}} \int_{0}^{t} \tau v(\tau, t) d \tau^{\prime}
$$

It follows from (21) and (23) in the limit as $t$ goes to infinity that

$$
\langle\tau\rangle=\frac{1}{\sigma}=\frac{\mathrm{V}_{\mathrm{m}}}{\dot{\mathrm{V}}_{\mathrm{r}}}
$$

Thus the mean age of mantle reprocessing, when the reprocessing rate is constant, is the mantle flux time, i.e., the time for the entire mantle volume, $V_{m}$, to flux through the melting region. We also found in the numerical calculations that the mean residence $t i m e, t_{r}$, was approximated by the flux time $t_{f}$.

At present, with a plate generation rate of $3 \mathrm{~km}^{2} / \mathrm{yr}$ [Chase, 1972] and a degree of partial melting of $20 \%$ [cf. Gast, 1968], the mean age from (19) and (24) is $10 \mathrm{~b} . y$. if the whole mantle is being sampled and $3.5 \mathrm{~b} . \mathrm{y}$. if only the upper mantle is being sampled. These ages are quite large in comparison with the 1-2 b.y. age of the mantle estimated from isotope systematics [Brooks et al.,1976; Chase, 1981], but in Appendix $B$ we show that these model ages are reduced considerably when reasonable increases in past convection rates are accounted for. In particular, from a consideration of a wide range of model 
parameters, the model ages vary between 500 m.y. and 2.5 b.y. The apparent age of 1-2 b.y., as observed, is consistent with the rate of recycling and suggests that the variation in isotopic ratios (in particular, the apparent isochrons) may be largely controlled by plate scale convection and the corresponding large-scale recycling.

\section{Summary and Conclusions}

Mixing of chemical tracers has been investigated in two-dimensional flows constrained by fundamental features of plate tectonics. These features are the unsteady kinematics of the plates and the introduction of chemical anomal ies at subduction zones. The following were incorporated into the velocity boundary conditions of full convection calculations: uniform velocity across plates, symmetrical spreading at ridges, asymmetrical convergence at trenches, migration of ridges, and migration of trenches toward the subducting plate. Only the large-scale flow associated with plate motion has been studied; by choosing Rayleigh numbers scaled down from mantle values, we have purposely suppressed small scale flow instabilities of the thermal boundary layers. Furthermore, the tracers are passive and generate no buoyancy of their own. Although the calculations are highly simplified, we expect them to provide a first-order approximation to mixing by the large-scale flow and to provide a sound base for more realistic calculations.

We conclude from our study that chemical anomal ies, manifest as strongly nonrandom distributions in tracer density that exist on many length scales, persist for up to a few billion years, when scaled to the mantle. The specifics and implications of this general conclusion follow.

1. The primary reason for the longevity of small-scale anomalies is that material entering the flow at margins is preferentially transferred to adjacent cells, where the flow is reversed. The reversed flow partially unmixes the previously sheared recycled material. Unmixing is manifest as clumps where the density of tracers is high. These folds or clumps persist longer than simple shearing indicates. The fold apex, where the density is highest, is in relative motion to the tracers themselves as new tracers flux through the apex. This feature is shown to be robust and independent of the particulars of the plate evolution model.

2. If the tracers had intrinsic chemical buoyancy (as subducted oceanic crust and sediments would have), then the high concentration of tracers in clumps could be an important localized source of buoyancy and could cause the tracers to segregate to the bottom or top depending on the sign of the intrinsic density. If the tracers had high heat production (as the subducted oceanic crust and sediments would have), then the clumps could lead to local ized thermal anomal ies within the mantle, although this effect will be muted by the shearing of clumps by the largescale flow.

3. Finite fluid elements are injected below the implicit "trenches," and they deform rapidly. The fraction of elements with strains of $f$ ive or less decays exponentially in time. The half-life of the decay is seven transit times (a transit time is the time to travel the box depth with the characteristic boundary velocity). The rate of straining fluid elements is not inconsistent with the persistence of clumps of tracers caused by unmixing.

4. Tracers have been spatially sampled in two ways, which may mimic sampling of the mantle by magmatism. This sampling clearly shows that temporal variations and concentration anomalies exist on many scales. Small-scale anomalies exist out to 40 transit times and are associated with dynamic folds. Large scale anomalies exist out to 100 transit times and are associated with the segregation of entire convection cells. These conclusions are independent of the way the mantle may be sampled by the formation of basalts beneath ridges. The existence of these chemical anomalies is in accord with the observation that the mantle is isotopically heterogeneous on many scales. The small-scale anomal ies associated with dynamical folds, may be analogous to the sources of some hot spots, like Tristan da Cunha and Gough, which are presumably composed of recycled material [Kurz et al., 1982] or to the sources of small seamounts, which have many isotopic and chemical similarities to the much larger hot spots [Zindler et al., 1984]. The large-scale anomal ies associated with the segregation of entire convection cells in the models could be related to the plate-scale isotopic anomaly in the Indian and Southern Atlantic oceans [Hart, 1984].

5. The survival time of tracer clumps, up to 40 transit times for the cases investigated, is first scaled to the mantle, assuming convection rates are constant. The survival times scale to $560 \mathrm{~m} . \mathrm{y}$. and $2.4 \mathrm{~b} . \mathrm{y}$. for upper and wholemantle convection, respectively. Because of the long time implied by these scalings, the change in convection rates with time is also considered. Scalings that assume the heat flux has decayed with a 2 b.y. half-life indicate that the clump survival times are reduced to $470 \mathrm{m.y}$. and $1.4 \mathrm{b.y}$. for upper and whole-mantle convection. This demonstrates that ancient isotopic anomalies can exist in a convecting mantle, even assuming that the mantle was convecting much more rapidly in the past.

6. The tracers were removed near the implicit "ridge" in order to simulate the reincorporation of fractionated mantle into the lithosphere. The average time tracers are resident in the flow from subduction to sampling is within $20 \%$ of the time expected for an area, equivalent to the box area, to flux through the sample region, the flux time. Furthermore, the sampling is well approximated by a random sampling model because the rate of sampling decays exponentially in time at the expected rate.

7. The residence times have been scaled to obtain model mean ages of the mantle. Residence time scaling depends on sampling depth and the rate of convection; these two quantities have been considered in a parameterized thermal history model. For a wide range of parameters, model mean ages vary between $500 \mathrm{~m} . \mathrm{y}$. and $1.3 \mathrm{~b} . \mathrm{y}$. for upper mantle convection and between $900 \mathrm{~m} . \mathrm{y}$. and $2.3 \mathrm{~b} . y$. for whole-mantle convection. In the case of the whole-mantle convection scenario, the results bracket the approximate $1.8 \mathrm{~b} . \mathrm{y} . \mathrm{Rb}-\mathrm{Sr}$ and $\mathrm{Pb}-\mathrm{Pb}$ apparent isochrons of OIB and MORB ; this suggests that much of the isotopic variation observed for mantle-derived basalts may result 


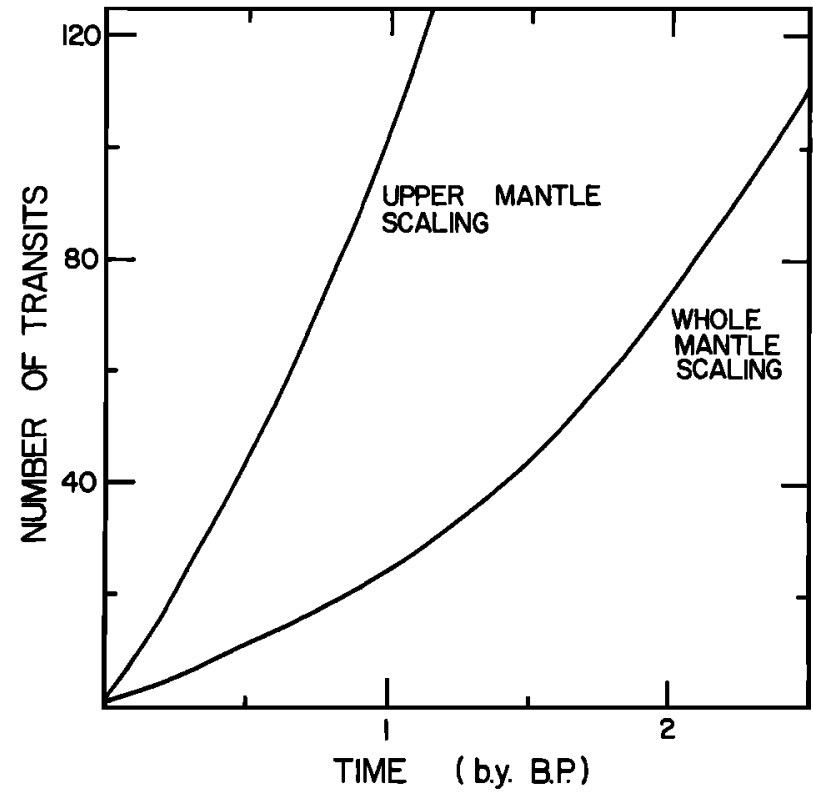

Fig. 10. Cumulative number of transits of the mantle for progressively greater ages before the present, assuming that the heat flux half-life is 2 b.y. and the present plate velocity is $5 \mathrm{~cm} / \mathrm{yr}$. These curves allow the survival time of clumps of tracers to be scaled to the mantle. The survival time of clumps, which depends only on accumulated strain, was on average 40 transit times.

from large-scale recycling driven by plate-scale thermal convection.

\section{Appendix A: Effects of Thermal History on Survival Time}

We will now consider the likely effects of increased convective rates in the past on scalings of survival times. In order to do this we will need to relate the convective velocities to the heat flux, so that a plate velocity model can be determined from a thermal history model. It can be shown from the boundary layer theory of convection [cf. Turcotte and Oxburgh, 1967] that, to a good approximation,

$$
u=c q^{2}
$$

where $u$ is the average top horizontal convective velocity and $c$ is a constant [see Gurnis and Davies, 1985]. The strong temperature dependence of silicate rheology causes the earth's heat flux to approximately track the exponential decay in the activity of heat-producing elements [Davies, 1980b; Schubert et al., 1980]. The thermal history will be approximated here as

$$
q=q_{0} e^{-\gamma t}
$$

where $\gamma$ is the thermal history decay constant. The value of $\gamma$ depends mainly on the $K / U$ ratio assumed. The $\mathrm{K} / \mathrm{U}$ ratio for the mantle probably lies between $10^{4}$ and $2 \times 10^{4}$, with an upper (chondritic) limit of $8 \times 10^{4}$ [cf. Stacey, 1977]. These K/U values bracket thermal half-lives of 2.25 to 1.5 b.y., respectively. Low values of $\mathrm{K} / \mathrm{U}$ are suggested from the generally low ratios of all terrestrial rocks (and in particular from an analysis of very fresh MORB glasses; Jochum et al. [1983]. This suggests that the thermal half-life is close to $2 \mathrm{~b} . \mathrm{y}$.

Because survival time depends on the accumulated strain, it is proportional to the total distance traversed by the fluid elements. The increased velocities will progressively decrease the transit time for progressively greater ages. The time, $t_{n D}$, to make $n$ transits of the mantle of depth $D$ is found by substituting (A2) into (A1) and integrating ( $A 1$ ) backward in time:

$$
t_{n D}=\frac{1}{2 Y} \ln \left[\frac{2 n D \gamma}{U_{p}}+1\right]
$$

where $U_{p}$ is the present plate velocity. In Figure 10, (A3) is plotted for the two convection scenarios. A thermal half-life of 2 b.y. and a present plate velocity of $5 \mathrm{~cm} / \mathrm{yr}$ was assumed for both cases. The scaled times are reduced from those obtained, assuming constant rates. For the upper mantle scenario, a tracer clump, which survives 40 transit times, scales to $470 \mathrm{~m} . \mathrm{y}$.; this compares with $560 \mathrm{~m} . \mathrm{y}$. for constant rates of convection. For the whole-mantle case, 40 transit times scales to 1.4 b.y., compared with 2.4 b.y. for a constant rate.

\section{Appendix B: Effects of Thermal History} on Residence Times

Two time dependent quantities arise in the scaling of the residence times: the melting depth $d_{m}$ and the areal plate velocity $\dot{A}$. The variation in plate or convective velocities was studied in Appendix $A$. The depth of the mantle reprocessing region and how it varies with an evolving mantle geotherm are fairly uncertain.

The temporal variation of $d_{m}$ can be constrained if the mantle solidus and the temporal variation of the geotherm can be estimated. The solidi of candidate mantle rocks have a slope greater than the adiabat [cf. Stacey, 1977], so that as the mantle temperature increases, the depth at which the geotherm crosses the solidus increases. In Figure 11 we show average mantle geotherms for progressively higher average mantle temperatures. Two solidi are also displayed and were estimated from the high pressure experiments on dry peridotite and $0.1 \% \mathrm{H}_{2} \mathrm{O}$-saturated pyrolite by Wyllie [1971] and Ringwood [1975] and extrapolated to depth with the theoretical solidus of Kennedy and Higgins [1972]. The large spread between the two solidi in Figure 11 is due to the effect of the water content of the mantle, which is uncertain. A very simple characterization of the increase of melting depth on internal temperature is

$$
d_{m}=\phi\left(T-T_{p}\right)+d_{p}
$$

where $T_{P}$ and $T$ are the temperatures at which the solidus and geotherm intersect (subscript $p$ denoting the present) and $\phi$ and $d_{p}$ are free 


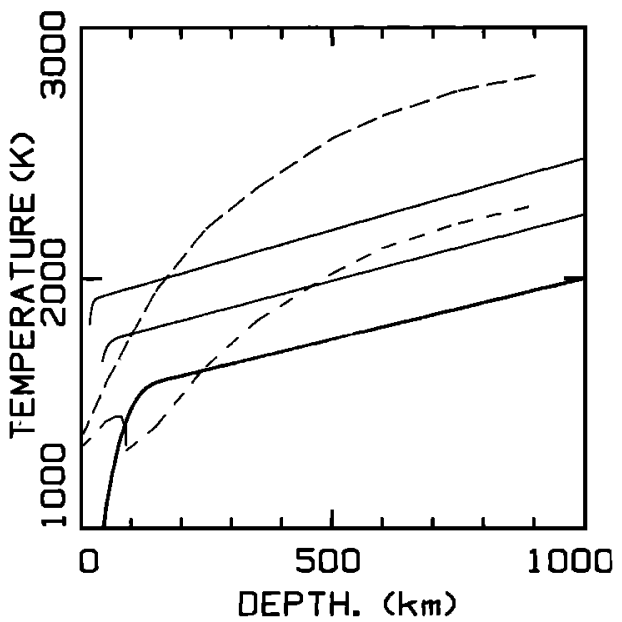

Fig. 11. Average mantle geotherms and estimates of mantle melting curves. The lowest geotherm (heavy solid line) is an estimate of the present average oceanic mantle. Higher geotherms are for $10 \%$ and $20 \%$ higher mean temperatures. Solidi for $0.1 \% \mathrm{H}_{2} \mathrm{O}$ saturated pyrolite (short-dashed line) and dry peridotite (long-dashed $l$ ine) are estimated from Ringwood [1975] and Wyllie [1971] and extrapolated to depth wi th the theoretical solidi of Kennedy and Higgins [1972]. The figure illustrates that as the mantle has cooled, the depth of the melting beneath ridges has probably become shallower.

parameters. The linear characterization is only an approximation. Three combinations of $a$ and $b$ have been chosen. If the current degree of partial melting needed to make MORB is about $20 \%$ [Gast, 1968] and the thickness of oceanic crust is $6 \mathrm{~km}$, then the present depth is $d_{p}$ - $\mathrm{d}_{\mathrm{Oc}} / \mathrm{F}=30 \mathrm{~km}$. To account for the uncertainty, the present depth is varied between 20 and 100 $\mathrm{km}$. The depth-temperature slopes, $\phi$, can be estimated from Figure 11 where the geotherms shown are $10 \%$ and $20 \%$ higher than the present. Depth-temperature slopes, $\phi$, of melting of 0.2 to $0.6 \mathrm{~km} / \mathrm{K}$ are reasonable.

A mean mantle temperature can be calculated from the average mantle heat flux. Because of the strong temperature dependence of silicate rheology [cf. Carter, 1976], the time variation of temperature can be calculated approximately from a thermal history of the earth via [Davies, 1979]

$$
\frac{\mathrm{T}}{\mathrm{T}_{\mathrm{p}}}=\left(\frac{\mathrm{q}}{\mathrm{q}_{\mathrm{p}}}\right)^{1 / \mathrm{m}}
$$

where $q$ is the mantle heat flux and $m$ is a constant of about 10 [Davies, 1979]. Equation (B2) concisely illustrates that temperature changes are strongly buffered against changes in heat flux.

The areal rate of plate generation must also be calculated from the heat flux of the mantle. As with the analysis of clump survival time, we assume an exponential thermal history; combining (A1) and (A2), we find

$$
\dot{A}(t)=\dot{A}_{0} e^{-2 \gamma t}
$$

where $\dot{A}_{0}$ is the initial areal rate of plate generation. Substituting (B1), (B2), and (B3) into (19), we find

$$
\begin{gathered}
\dot{V}_{r}=\dot{A}_{p} e^{-2 \gamma\left(t-\tau_{e}\right)} \\
\cdot\left[\phi T _ { p } \left(e^{\left.\left.-\gamma\left(t-\tau_{e}\right) / m_{-1}\right)+d_{p}\right]}\right.\right.
\end{gathered}
$$

where $\tau_{e}$ is the age of the earth (taken here to be 4.5 b.y.).

Before using (20) and (B4) to solve for the age distribution, we can integrate (BH) and calculate how many times the equivalent mantle volume has been recycled as a function of age. Results for four combinations of parameter values are shown in Figure 12, if the whole mantle is being sampled. To convert to upper mantle values, multiply the ordinate values by 2.95 . By inspecting curve 4, for example, in Figure 12, one can see that the equivalent to the entire mantle volume has passed through the oceanic crust/depleted lithosphere in the last $1.5 \mathrm{b.y.,}$ twice in the last 2 b.y., and four times in the last $3 \mathrm{~b} . y$. Longer thermal half-lives result in less reprocessing: curves 1 and 2 both have a $d_{p}=20 \mathrm{~km}$, but curve 1 has a thermal half-life of 1.5 b.y., while for curve 2 it is 1.5 times longer. Larger sampling depths result in greater rates of reprocessing: curves 1 and 3 both have the same thermal history, but the present sampling depth, $d p$, for curve 3 is a factor of 5 greater. By 2 b.y. B.P. the curves in Figure 12 become much steeper than might be generally thought, and this is mostly a manifes-

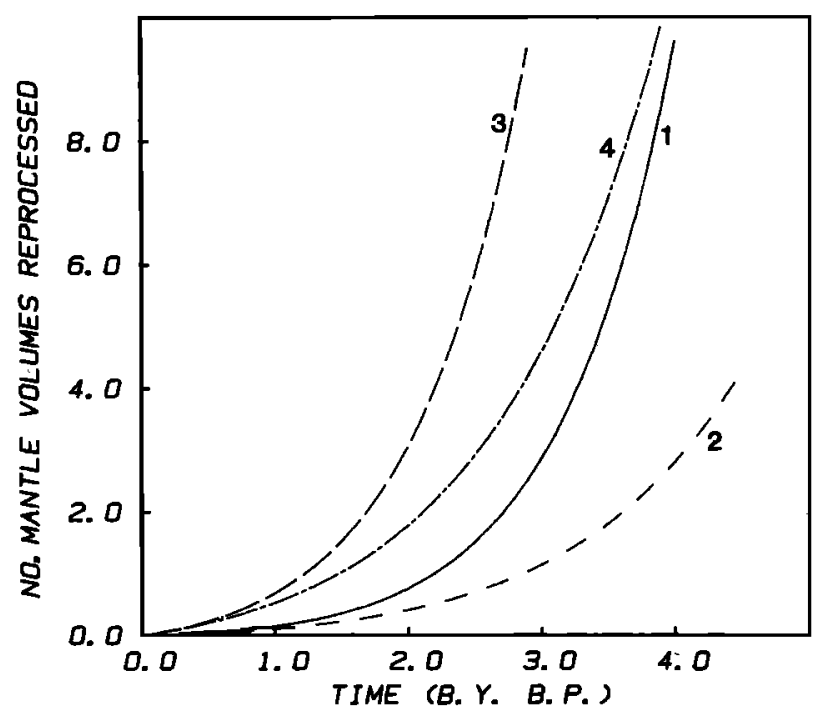

Fig. 12. Number of times the equivalent to the whole mantle has passed through the oceanic crust/depleted lithosphere by an integration of (B4) back in time for four sets of parameter values; the parameters describing each curve are given in Table $B 1$. The curves become very steep earlier than 2 b.y. B.P. (illustrating very rapid recycling) due to the dependence of velocity on heat flux to the second power. 
TABLE B1. Mean Ages of Mantle

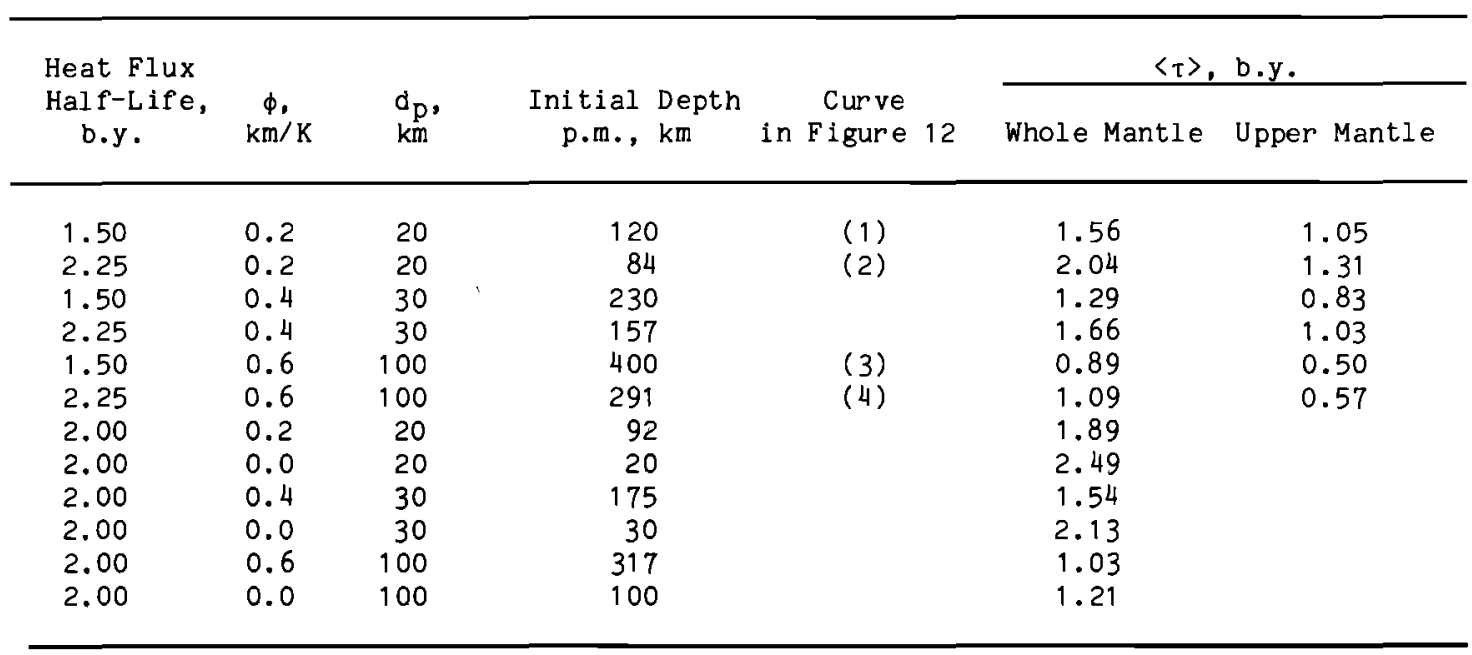

tation of (A1): that convective velocities go as the square of the heat flux.

No simple analytical solution exists for the age distribution in the nonsteady state when $\dot{V}_{r}$ varies as in (B4). The mean age, however, is easily calculated numerically by $f$ irst evaluating (20) and (B4) to obtain the age distribution and then by carrying out the integration of (23) on the age distribution to obtain the mean age of reprocessing, $\langle\tau\rangle$. As an initial condition, we assume that the mantle was isotopically homogeneous and of zero age. Listed in Table B1 are mean ages for convection confined both to the upper mantle and to the whole mantle. Note that the ages are not the same age (and actually less than the age) since one mantle volume has been processed. The half-life of the heat $f l u x$ and the constants $\phi$ and $d_{p}$ of (B1) are also varied. Despite the large spread between both input parameters and their resulting curves in Figure 12, the mean ages of reprocessing only vary between $500 \mathrm{~m} . \mathrm{y}$. and $2 \mathrm{b.y}$. (i.e., by a factor of 4). One reason for the small spread is the very vigorous reprocessing of the mantle before 2 b.y. (displayed for most parameter values, Figure 12); this effectively obliterates any age contribution prior to 2 b.y. B.P., and hence the spread in the mean ages is less than might be expected from a large uncertainty in the input parameters.

Despite the uncertainty surrounding the depth of sampling and how it has varied in the past, the greatest contribution to recycling is due to the increased convective velocities of the past. This is shown when the dependence of partial melt depth on temperature is ignored (by letting $\phi$ vanish): the mean ages increase only by a factor of $20-30 \%$ when the recycling depth remains constant. Thus unless vastly different length scales of melting are found to exist beneath ridges, the ages presented here should be representative of mantle reprocessing dominated by convective velocities.

Finally, is the lead isochron age consistent with the ages obtained in the case of random sampling of heterogeneities in the mantle? The mean ages just calculated (Table B1) certainly do bracket the lead isochron age of $1.8 \mathrm{~b} . \mathrm{y}$. (although they are in general less than the isochron age): the isochron age is certainly consistent with the hypothesis of recycling crustal materlal through the mantle, as is discussed in the main text.

\section{Appendix C: Comparison With Other Studies}

The conclusions reached here concerning the time scale over which spatial (or chemical) heterogeneity persists is contrary to the conclusions reached by Richter [1984] and Hof $f$ man and McKenzie [1985]. As best we can judge, these different conclusions result not only from differences in interpretation and perspective, but also from differences in the form of the flows (especially in their degree of unsteadiness) and in the intilal form of the chemical anomaly.

Richter [1984] and Hof fman and McKenzie [1985] emphasize the dispersion of anomalles and the mean properties of the stirring, with little regard to the details of spatial variations. Consider, for example, the last frames of Hoffman and McKenzie's Figures 12, 14, and 15. The authors emphasize how the initial square has become extremely contorted and that a large fraction of it has been drawn out into extremely fine streaks. Their figures clearly show this behavior. However, the authors fail to mention that much of the anomalous material is still in a few large blobs: a number of large chemical anomalies persist to 200-400 m.y. (the times they quote from upper mantle parameters). A measure of the "average" thickness of the anomalous material clearly fails to bring out all the relevant information.

The models also differ in their degree of unsteadiness. To appreciate this difference, consider the isotherms of the flow shown in Figure 4 of Richter [1984]. Within the interior of this $8 \times 1$ box there are an average of four descending limbs for the instants shown. Using the parameter values he gives and his equation (2) relating the velocity scale to the Rayleigh number, the time interval between the instants shown is about two transit times. As best we can judge, there is complete (or nearly complete) rearrangement of descending flow in these two 
A
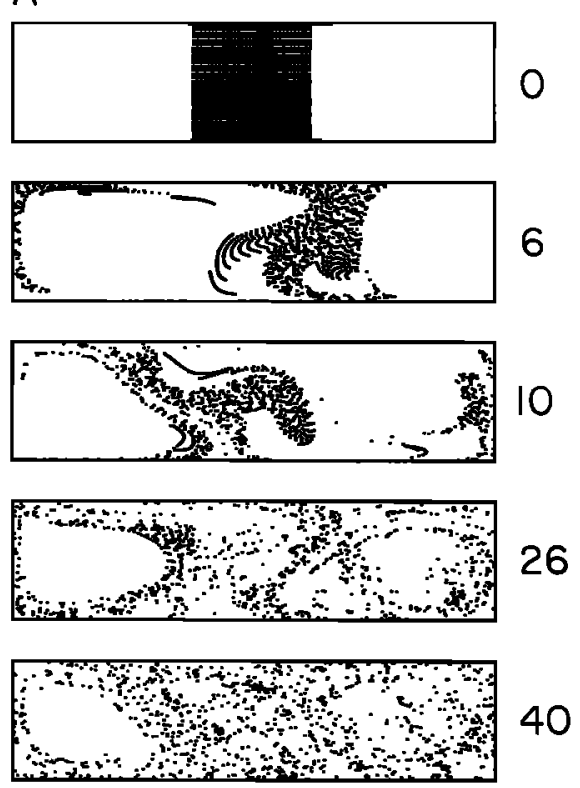

B

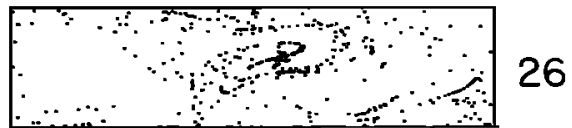

Fig. 13. Comparison of mixing when the mode of tracer introduction is varied. (a) Tracers introduced instantly in a unit square at $t=0$. (b) Tracers introduced at the margin of a cell. Values labeling each frame are the average time tracers have been in the flow (in transit times).

transit times. Richter et al. [1982] and Hof fman and MoKenzie [1985] employed the same flow. In the flows studied here, however, a comparable amount of rearrangement would occur in about five transit times. Now consider the mixing resulting from this flow. The second frame in Figure 6 of Richter [1984] is rescaled to four to six transit times. The tracers in this figure are plotted in a similar way to our Figure 3 ; in terms of the clumping of tracers, we qualitatively judge this to be mixed as much as our case 1 at 18 transit times. In terms of transit times, the flow Richter has used has a greater degree of unsteadiness and tends to mix anomalies more rapidly. The greater unsteadiness in those flows results from the relatively high Rayleigh number used in combination with constant viscosity and free-slip boundaries. The relevance of such models, which lack any semblance of a lithosphere, to the mantle remains to be demonstrated.

At the other extreme, olson et al. [1984] have considered mixing by completely steady, single-cell flows, which is fundamentally different from the mixing by the moderately unsteady flows studied in this paper. The stirring of individual fluid elements is different in the two cases. Consider the strain, $\delta$, of fluid elements introduced into a steady flow from a point near the margin of a cell, as was done here for an unsteady flow. The elements would be continuously deformed; the stirring experienced for all elements would be the same after each tracer has been in the flow for an equal period of time. Before some critical time, all elements would be deformed less than an amount, $\delta^{*}$, and after this critical time the strain of all elements would be greater than $\delta^{*}$. A plot similar to our Figure 6 (the fraction of fluid elements strained by $\delta^{*}$ or less versus time) could not be constructed. It is difficult to make a quantitative comparison with our models in these terms.

On the other hand, as was shown in the main text, the stirring of elements in unsteady flows is much different because of the occurrence of partial unmixing. Unmixing is obviously absent from steady flows, like the one studied by olson et al. [1984], although it should be present in the unsteady flows studied by Richter [1984] and Hoffman and McKenzie [1985].

Finally, and perhaps most importantly, the apparent differences in persistence of heterogeneities depend upon the initial distribution of tracers. In steady flows, elements at the center of cells, for example, experience only minimal deformation. In the situation investigated by olson et al. [1984], where the flow is steady and the tracer distribution uniform, the stirring rate may be considerably smaller than the stirring rate for the unsteady flow investigated here, for example, because of the large proportion of tracers near the center of a cell. The placement of tracers either uniformiy over cells or within the center of cells has no obvious relevance to known geological processes. Anomalies to be mixed by mantle convection enter at margins either from subduction or from entrainment of material from a boundary or adjacent layer.

Despite its lack of geological motivation, we have, for comparison, followed Richter et al. [1982], Richter [1984], and Hoffman and McKenzie [1985] and placed a uniform unit square of tracers in the center of the box at time zero for the flow of case 1 (shown in Figure 3). As shown in Fig 13a, the anomaly is efficiently stirred and dispersed by the flow and the longest surviving dense (small-scale) accumulation of tracers seems to persist, at most, to time 26 . We now compare this with the case of tracer entry from the margin of a cell (case 1), except now all tracers are left in the flow. Because in the margin entry case the tracers were introduced over the first 10 transit times, we must use this case at time 31 so that the tracers have been in the flow for an average of 26 transit times. This instant is shown in Figure $13 \mathrm{~b}$. For both cases the tracers have been plotted in the same way. The margin entry case clearly shows much more intense spatial heterogeneity, especially on a small scale. When the tracers are introduced at the margins of convection cells, as opposed to instantly over a large patch, much more heterogeneity is observed to persist.

In summary, there are several reasons for the differences between the conclusions based on calculations presented here and those based on other calculations. The differences are mainly due to our emphasis on spatial heterogeneity as opposed to a mean mixing property, to the use of flows with less unsteadiness relative to average flow velocities, and to the use of 
chemical anomalies with different initial geometries. These differences will have to be characterized more quantitatively in future studies, and optimum measures of mixing and spatial heterogeneity found.

\section{References}

Allègre, C. J., T. Staudacher, P. Sarda, and M. Kurtz, Constraints on evolution of earth's mantle from rare gas systematics, Nature 303, 762-766, 1983.

Brooks, C., S. R. Hart, A. W. Hofmann, and D. E. James, Rb-Sr mantle isochrons from oceanic regions, Earth Planet. Sc1. Lett., 32, 51-61, 1976.

Brown, L., J. Klein, R. Middleton, I. S. Sacks, and $\mathrm{F}$. Terra, ${ }^{10} \mathrm{Be}$ in island-arc volcanics and implications for subduction, Nature, 299, 718-720, 1982.

Burke, K., J. F. Dewey, and W. S. F. Kidd, Dominance of horlzontal movements, arc and mirocontinental collisions during the later permobile regime, in The Early History of the Earth, edited by B. F. Windley, John Wiley, New York, pp. 113-129, 1976.

Carter, N. L., Steady state flow of rocks, Rev. Geophys. Space Phys., 14, 301-360, 1976.

Chase, C. G.. The n-plate problem of plate tectonics, Geophys. J. R. Astron. Soc., 29, 117-122, 1972 .

Chase, C. G., Oceanic island lead: Two-stage histories and mantle evolution, Earth Planet. Sci. Lett., 52, 277-284, 1981 .

Church, S. E., and M. Tatsumoto, Lead isotope relations in oceanic ridge basalts from the Juan da Fuca-Gorda ridge area, N.E. Pacific Ocean, Contri. Mineral. Pertrol. 53, 253-279, 1975.

Conte, S. D., and C. de Boor, Elementary Numerical Analysis: An Algorithmic Approach, 396 pp., McGraw-Hill, New York, 1972.

Davies, G. F., Thickness and thermal history of continental crust and root zones, Earth Planet. Sci. Lett., 44, 231-238, 1979.

Davies, G. F., Review of oceanic and global heat flow estimates, Rev. Geophys. Space Phys., 18, 718-722, 1980a.

Davies, G. F., Thermal histories of convective earth models and constraints on radiogenic heat production in the earth, J. Geophys. Res., 85, 2517-2530, 1980b.

Davies, G. F., Geophysical and i sotopic constraints on mantle convection: An interim synthesis, J. Geophys. Res., 89, 6017-6060, 1984a.

Lavies, G. F., Plate-mantle coupling in timedependent numerical convection models: Improved plate simulations (abstract), Eos Trans. AGU $65,1092,1984 \mathrm{~b}$.

Davies, G. F., Mantle convection under simulated plates: Effects of heating modes and ridge and trench migration, and implications for the core-mantle boundary, bathymetry, the geoid, and Benioff zones, Geophys. J.R. Astron. Soc., 84, 153-183, 1986.

Fisher, D. E., Radiogenic rare gases and the evolutionary history of the depleted mantle, J. Geophys. Res., 90, 1801-1807, 1985.

Fyfe, W. S., The geochemical cycle of uranium, Trans. R. Soc. London, Ser. A, 291, 433-445, 1979.
Gast, P. W., Trace element fractionation and the origin of tholeiitic and alkaline magma types, Geochim. Cosmich. Acta, 32, 1057-1086, 1968.

Gurnis, M., and G. F. Davies, Simple parametric models of crustal growth, J. Geodyn., 3 , 105-135, 1985.

Hager, B. H., and R. J. O'Connell, Kinematic models of large-scale flow in the earth's mantle, J. Geophys. Res., 84, 1031-1048, 1979.

Hart, S. R., A large-scale isotopic anomaly in the southern hemisphere mantle, Nature, 309, 753-757, 1984.

Heller, J. P., An unmixing demonstration, Am. J. Phys., 28, 348-353, 1960.

Hilde, T. W. C., Sediment subduction versus accretion around the Paclfic, Tectonophysics 99, 381-397, 1983.

Hoffman, N. R. A., and D. P. MoKenzie, The destruction of geochemical heterogeneities by differential fluid motions during mantle convection, Geophys. J. R. Astron. Soc., 82, 163-206, 1985.

Hofmann, A. W., and W. M. White, Mantle plumes from ancient oceanic crust, Earth Planet. Sci. Lett., 57, 421-436, 1982.

Honda, S., A preliminary analysis of convection in a mantle with a hetergeneous distribution of heat-producing elements, Phys. Earth Planet. Int., 34, 68-76, 1984.

Hussong, D. M., and $S$. Uyeda, Tectonic processes and the history of the Mariana ar c: A synthesis of the results of Deep Sea Drilling Project Leg 60, in Initial Rep. Deep Sea Drilling Proj., 60, 909-929, 1982.

I sacks, B., J. Oliver, and L. R. Sykes, Sei smology and the new global tectonics, J. Geophys. Res.. 73, 5855-5899, 1968.

Jochum, K. P., A. W. Hofmann, E. Ito, H. M. Seufert, and $W$. M. White, $K, U$ and $T h$ in mid-ocean ridge basalt glasses and heat production, $K / U$ and $K / R b$ in the mantle, Nature, 306, $431-436,1983$.

Kennedy, G. C., and G. H. Higgins, Melting temperatures in the earth's mantle, Tectonophysics, 13, 209-228, 1972.

$\operatorname{Kur} \frac{1}{z}$, M. D., W. J. Jenkins, and S. R. Hart, Hel ium isotopic systematics of oceanic islands and mantle heterogeneity, Nature, 297, 43-47, 1982.

Kurz, M. D., W. J. Jenkins, S. R. Hart, and D. Clague, Helium isotopic variations in volcanic rocks from Loini Seamount and the Island of Hawai i, Earth Planet. Sci. Lett., $66,388-406,1983$.

Loper, D. E., A simple model of whole-mantle convection, J. Geophys. Res., 90, 1809-1836, 1985.

McKenzie, D., Finite deformation during fluid flow, Geophys. J. R. Astr. Soc., 58, 689$715,1979$.

McKenzie, D. P., and N. O. Weiss, Speculations on the thermal and tectonic history of the earth, Geophys. J. R. Astron. Soc., 42, 131174,1975

McKenzie, D. P., J. M. Roberts, and N. O. Weiss, Convection in the earth's mantle: Towards a numerical simulation, J. Fluid Mech., 62 . 465-538, 1974.

Meijer, $\mathrm{A}, \mathrm{Pb}$ and $\mathrm{Sr}$ isotopic data bearing 
on the origin of volcanic rocks from the Mariana island-arc system, Geol. Soc. Am, Bull. 87, 1358-1369, 1976.

$0^{\prime}$ Connell, R. J., and B. H. Hager, on the thermal state of the earth, in Physics of the Earth's Interior, edited by A. Dzeiwonski and E. Boschi, North-Holl and, Amster dam, 1980.

Olson, P., D. A. Yuen, and D. Balsiger, Mixing of passive heterogeneities by mantle convection, J. Geophys. Res., 89, 425-436, 1984.

Richter, F. M., Time and space scales of mantle convection, in Patterns of Change in Earth History, edited by H. D. Holland and A. F. Trendali, pp. 271-289, Dahlem Konferenzen, Berlin, 1984.

Richter, F. M., S. F. Daly, and H.-C. Nataf, A parameterlzed model for the evolution of isotopic heterogeneities in a convecting system, Earth Planet. Sci. Lett., 60, 178$194,1982$.

Ringwood, A. E., Composition and Petrology of the Earth's Mantle, 618 pp., McGraw-Hill, New York, 1975.

Ringwood, A. E., Phase transformations and differentiation in subducted 1 ithosphere: Implications for mantle dynamics, basalt petrogenesis, and crustal evolution, J. Geol., $90,611-643,1982$.

Schubert, G., D. Stevenson, and P. Cassen, Whole planet cooling and the radiogenic heat source content of the earth and moon, J. Geophys. Res., 85, 2531-2538, 1980.

Sleep, N. H., Tapping of magmas from ubiquitous mantle heterogeneities: An alternative to mantle plumes ?, J. Geophys. Res., 89, 10029$10041,1984$.

Stacey, F. D., Physics of the Earth, 2nd ed., 414 pp., John Wiley, New York, 1977.

Sun S.-S., and G. N. Hanson, Evolution of the mantle: Geochemical evidence from alkali basalts, Geology, 3, 297-302, 1975.

Tatsumoto, M., Isotopic composition of lead in oceanic basalts and its implication to mantle evolution, Earth Planet. Sci. Lett., 38, 63-87, 1978.

Turcotte, D. L., and E. R. Oxburgh, Finite amplitude convection cells and continental drift, J. Fluid Mech. 28, 29-42, 1967.

Von Huene, R., M. Langseth, N. Nasu, and H. Okada, A summary of Cenozoic tectonic history along the IPOD Japan Trench, Geol. Soc. Am. Bull., 93, 829-846, 1982.

Wasserbur , G. J., and D. J. DePaolo, Models of earth structure inferred from neodymium and strontium isotopic abudances, Proc. Natl. Acad. Sci. USA, 76, 3594-3598, 1979.

White, W. M., and A. W. Hof mann, $\mathrm{Sr}$ and $\mathrm{Nd}$ i sotope geochemistry of oceanic basalts and mantle evolution, Nature, 296, 821-825, 1982.

White, W. M., and J. Patchett, $\mathrm{Hf}-\mathrm{Nd}-\mathrm{Sr}$ isotopes and incompatible element abundances in island arcs: Implications for magma origins and crust-mantle evolution, Earth Planet. Sci. Lett. 67, 167-185, 1984.

Wyllie, P. J., The Dynamic Earth, 415 pp., John Wiley, New York, 1971.

Yuen, D. A., and W. R. Peltier, Mantle plumes and the thermal stability of the D" layer, Geophys. Res. Lett., 7, 625-628, 1980.

Yuen, D. A., W. R. Peltier, and G. Schubert, on the existence of a second scale of convection in the upper mantle, Geophys. J. R. Astron. Soc, 65, 171-190, 1981 .

$\mathrm{Z}$ indler, $\mathrm{A}$., H. Staudigel, and R. Batiza, Isotope and trace element geochem1stry of young Pacif ic sea mounts: Implications for the scale of upper mantle heterogeneity, Earth Planet. Sc1. Lett. . 70. 175-195, 1984.

G. F. Davies and M. Gurnis, Research School of Earth Science, Australian National University. P.0. Box 4, Canberra, ACT 2600, Australia.

(Received August 15, 1984; revised November 21,1985 ; accepted January 3, 1986.) 